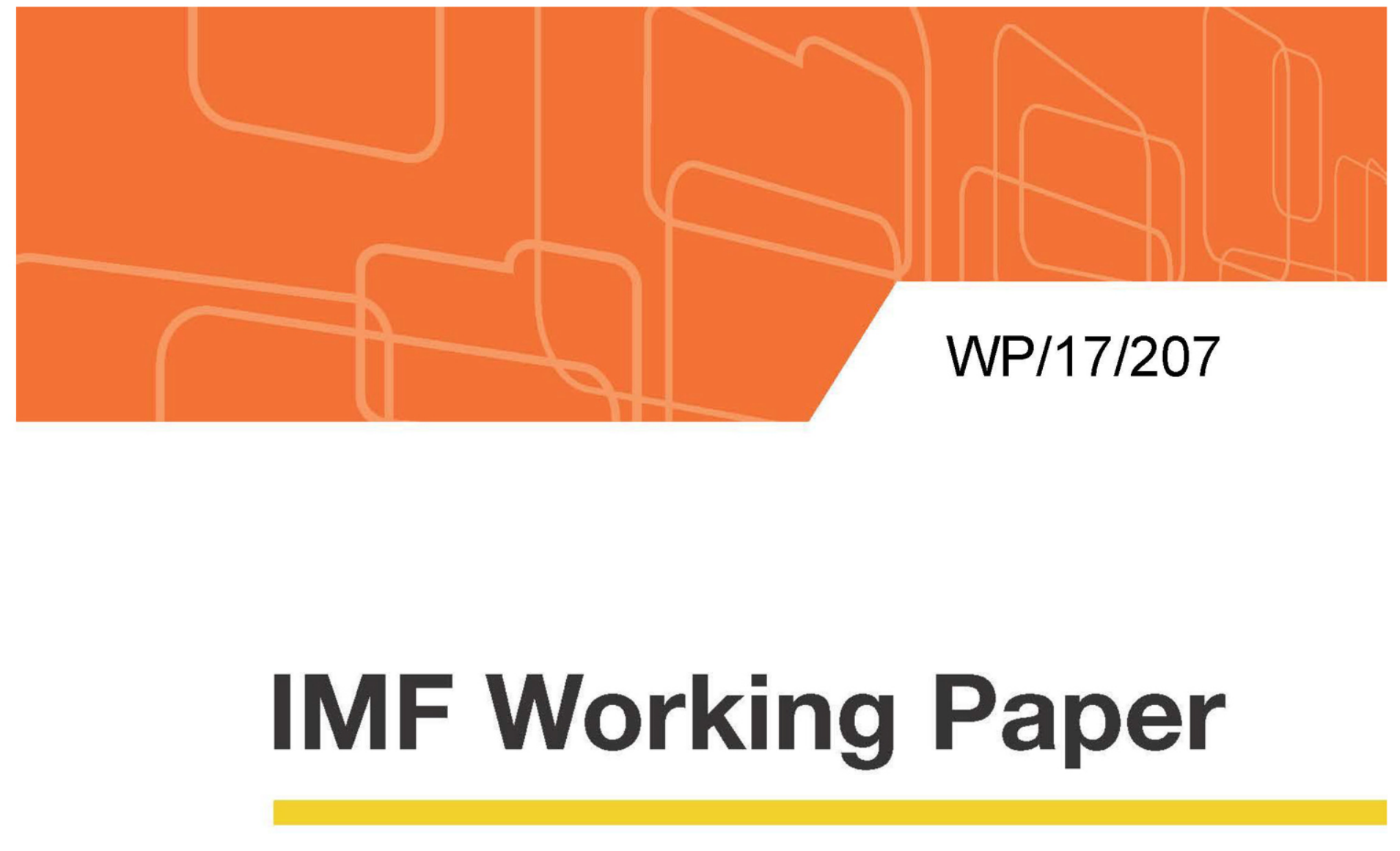

\title{
FX Intervention in the New Keynesian Model
}

by Zineddine Alla, Raphael Espinoza and Atish R. Ghosh

IMF Working Papers describe research in progress by the author(s) and are published to elicit comments and to encourage debate. The views expressed in IMF Working Papers are those of the author(s) and do not necessarily represent the views of the IMF, its Executive Board, or IMF management. 


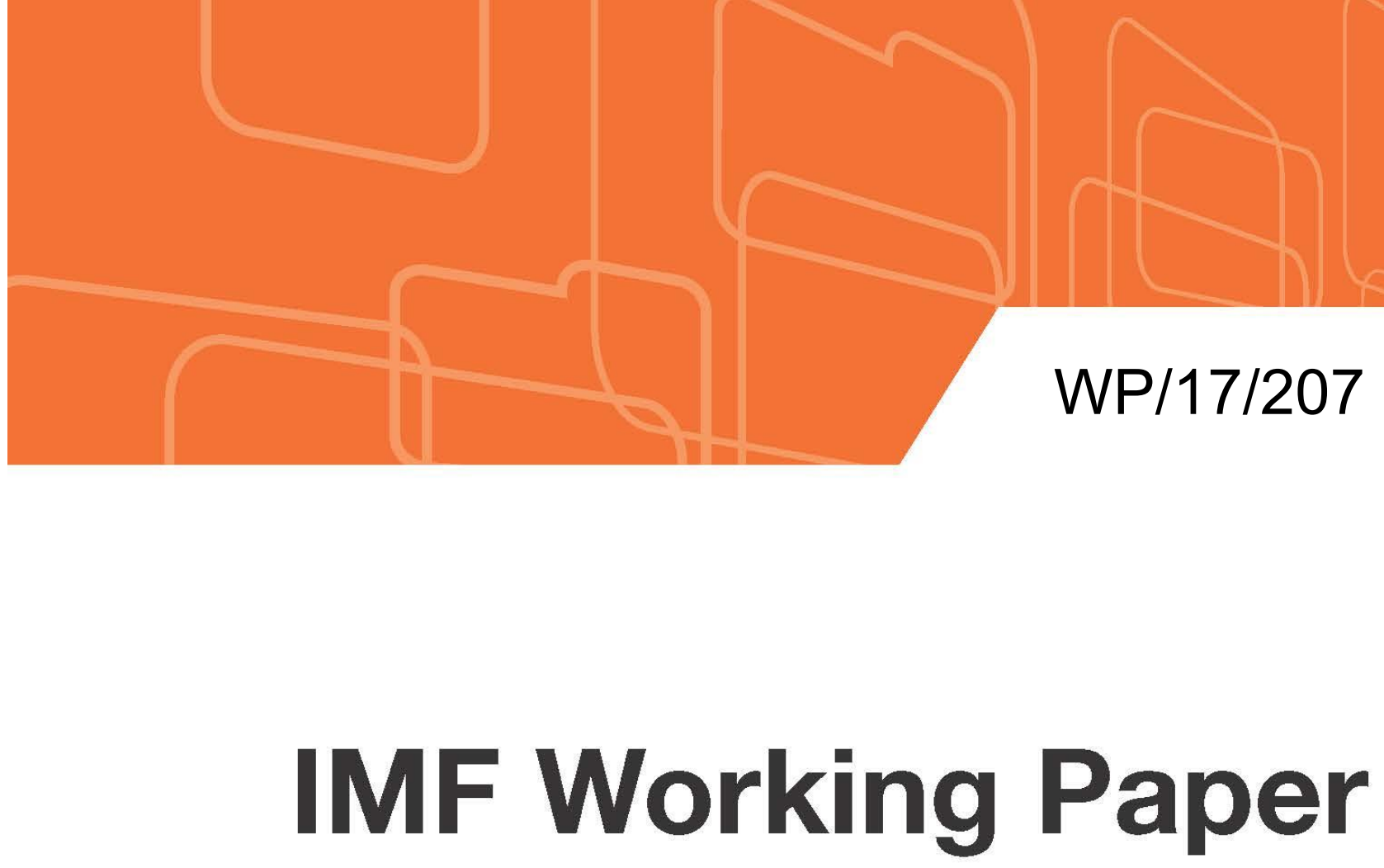

FX Intervention in the New Keynesian Model

by Zineddine Alla, Raphael Espinoza and Atish R. Ghosh

IMF Working Papers describe research in progress by the author(s) and are published to elicit comments and to encourage debate. The views expressed in IMF Working Papers are those of the author(s) and do not necessarily represent the views of the IMF, its Executive Board, or IMF management.

I N T E R N A T I O N A L M O N E T A R Y F U N D 


\title{
IMF Working Paper
}

Research Department and Strategy, Policy, \& Review Department

FX Intervention in the New Keynesian Model

Prepared by Zineddine Alla, Raphael Espinoza and Atish Rex Ghosh*

\author{
Authorized for distribution by Atish R. Ghosh
}

September 2017

\section{This Working Paper should not be reported as representing the views of the IMF.} The views expressed in this Working Paper are those of the author(s) and do not necessarily represent those of the IMF or IMF policy. Working Papers describe research in progress by the author(s) and are published to elicit comments and to further debate.

\begin{abstract}
We develop an open economy New Keynesian Model with foreign exchange intervention in the presence of a financial accelerator mechanism. We obtain closed-form solutions for the optimal interest rate policy and FX intervention under discretionary policy, in the face of shocks to risk appetite in international capital markets. The solution shows that FX intervention can help reduce the volatility of the economy and mitigate the welfare losses associated with such shocks. We also show that, when the financial accelerator is strong, the risk of equilibrium indeterminacy (self-fulfilling currency and inflation movements) is high. We determine the conditions under which indeterminacy can occur and highlight how the use of FX intervention reinforces the credibility of the central bank's inflation targeting regime.
\end{abstract}

JEL Classification Numbers: E52; E58; F31

Keywords: Central bank reserves; Speculative attack; Portfolio balance model; Equilibrium determinacy; Capital flows; Capital controls; Open Economy New Keynesian Model.

Author's E-mail Addresses: zineddine.alla@gmail.com; respinoza@imf.org; aghosh@imf.org

\footnotetext{
* We are grateful for the comments and suggestions from Suman Basu, Paolo Cavallino, Nicolas Coeurdacier, Emmanuel Farhi, Philippe Martin, Helene Rey, Lars Svensson, Pablo Winant, Felipe Zanna, and from seminar participants at the IMF and at the Bank of England. The views expressed in this paper are solely those of the authors and do not represent those of the IMF or IMF policy.
} 
Contents

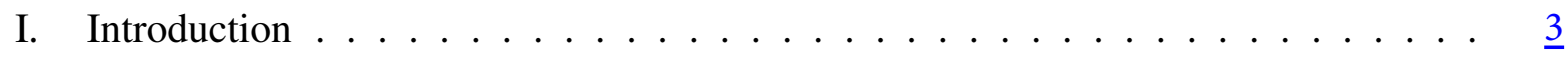

II. Related Literature . . . . . . . . . . . . . . . . . . . $\underline{5}$

III. A Small Open Economy . . . . . . . . . . . . . . . . . . . $\underline{8}$

A. Households ...................... . . 8

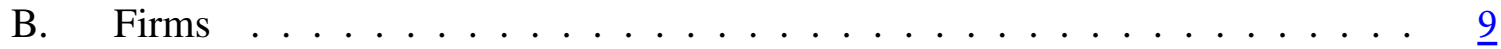

C. The Central Bank, Sterilized Interventions and the Government . . . . . . . 11

D. Exchange Rates and the Terms of Trade . . . . . . . . . . . . . 14

E. Equilibrium Conditions . . . . . . . . . . . . . . . . . $\frac{14}{17}$

F. The Log-linearized Framework . . . . . . . . . . . . . . . . . $\frac{17}{19}$

G. Loss Function . . . . . . . . . . . . . . . . . . . $\underline{19}$

IV. Optimal Stabilization Policy following Risk Premium Shocks . . . . . . . . . . . . 21

A. Optimal use of FX Intervention following Risk Premium Shocks . . . . . . . $\underline{21}$

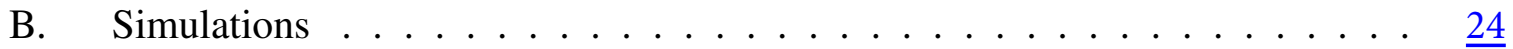

V. FX Intervention and Speculative Attacks . . . . . . . . . . . . 25

A. Optimal Policy .................... . . . $\frac{26}{26}$

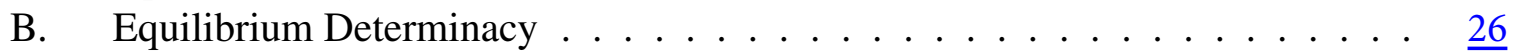

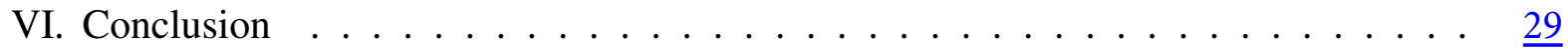

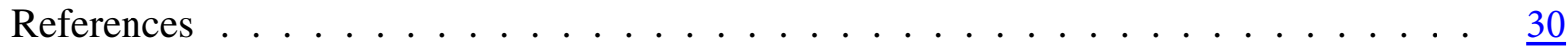

Appendices

I. First-order Conditions for Calvo Price Setting . . . . . . . . . . . . 33

II. Derivation of the Intertemporal Budget Constraint $\ldots \ldots \ldots$. . . . . . . 33

III. Derivation of the Loss Function $\ldots \ldots \ldots \ldots \ldots$

IV. Proof of Proposition $1 \ldots \ldots \ldots \ldots$

Figures

1. The Effects of a Risk-Premium Shock under Optimal Discretionary Policy........ $\underline{37}$

2. Welfare Losses following an Exogenous Risk Premium Shock (5 percent shock,

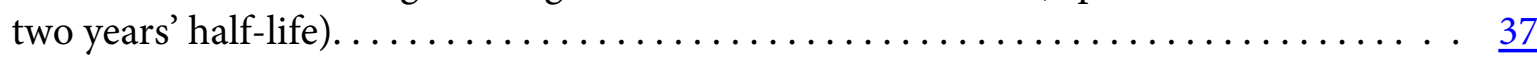

3. Welfare Gains from using FX Intervention following an Exogenous Risk Premium Shock . . . . . . . . . . . . . . . . . . . . . . . . . . . .

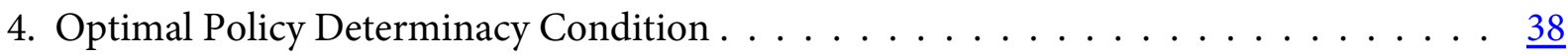




\section{INTRODUCTION}

Despite the move toward greater exchange rate flexibility over the past 30 years, many central banks - including some with inflation-targeting frameworks - seem to have twin objectives of price stability and (at least some degree of) exchange rate stability. ${ }^{2}$ The principal instruments at their disposal are the policy interest rate and sterilized intervention in the foreign exchange (FX) market. ${ }^{3}$ But in the canonical New Keynesian model (e.g. Gali and Monacelli (2005)), the policy interest rate suffices for stability because the two objectives of stable inflation and a zero output gap coincide (the 'divine c oincidence'): there is no exchange rate objective, and therefore no need for FX intervention. Our purpose in this paper is to examine whether shocks (e.g., "risk-on/risk-off" episodes) in international capital markets can give rise to a micro-founded rationale for sterilized intervention to stabilize the economy and to analyze how FX intervention affects the credibility of an inflation targeting regime.

Our framework, building on the canonical New Keynesian model, incorporates three key features. First, the existence of shocks in international capital markets that result in variations in the cost of capital to the economy. Second, financial frictions in international capital markets that break uncovered interest rate parity (UIP), and render sterilized intervention effective through a form of portfolio balance channel. Third, a working-capital requirement for firms' production that amplifies the effects of the capital market shocks on the real economy. ${ }^{4}$

The issues we examine are of salience to both emerging market and advanced economies. As is well known, many emerging market central banks exhibit a "fear of floating" (Calvo and Reinhart (2002)), and will often respond to capital inflow surges and sudden stops using monetary and exchange rate (FX intervention) policies. Increasingly since the global financial crisis, however, central banks of small, open, advanced economies have started intervening in the foreign exchange market as well. For instance, in September 2012, faced by a combination of low growth, negative core inflation, and weak credit, the Czech National Bank (CNB) signaled that it was considering using FX intervention as an additional instrument against a strengthening currency (IMF (2013)). In November 2013, the CNB calibrated its exchange rate target to its effect on aggregate demand and inflation and began intervening in the FX market, which proved effective in anchoring exchange rate and inflationary expectations, thus boosting aggregate demand (Alichi et al. (2015)).

\footnotetext{
${ }^{2}$ According to the IMF classification, around one-third of all countries either de jure or de facto manage their exchange rate.

${ }^{3}$ Sterilized intervention consists of the central bank purchasing or selling foreign currency-denominated assets with corresponding sales or purchases of domestic currency assets in order to leave the money supply unchanged. If FX intervention is not sterilized, then it does not constitute a separate instrument from monetary policy.

${ }^{4}$ See Farhi and Werning (2014) or Woodford (2012) for models in which financial frictions justify the use of capital controls or unconventional policies. In practice, FX intervention is the most commonly used tool after the policy interest rate.
} 
Switzerland provides a similar example, albeit with an additional twist. As the Euro crisis reduced investors' appetite for Euro-denominated assets, financial flows to Switzerland threatened to appreciate the Swiss Franc above the ceiling announced in 2011 by the Swiss National Bank (SNB). The central bank backed the announcement with aggressive intervention, leading the SNB's reserves to swell above US\$ 500 billion in 2013, more than doubling its stock of reserves (IMF (2014)). Although the policy was initially effective in mitigating capital inflows and stabilizing the exchange rate, a renewed wave of capital inflows at the end of 2014 (driven by poor Euro area prospects and ECB quantitative easing) made the situation untenable: not only was reserve accumulation becoming very costly, but there were also fears that markets were anticipating a revaluation, and that such expectations would result in a self-fulfilling strengthening of the currency as the ballooning reserves became unsustainably costly to hold. In short, one policy instrument was not enough to contain speculative flows and the Swiss National Bank decided to cut its policy rate from -0.25 to -0.75 percent in January $2015 .^{5}$

These examples are illustrative of the potential sources of instability against which monetary and exchange rate (FX intervention) policies may be useful. In the Czech case, the country was facing a real shock to aggregate demand against which the additional instrument of FX intervention proved effective. In the Swiss case, there was the additional risk of self-fulfilling exchange rate expectations driving the currency to arbitrary levels-a sort of "reverse speculative attack" wherein investors, anticipating a strengthening of the currency, force the revaluation of the exchange rate.

The framework we develop is well-suited to analyzing optimal policy in the face of such instabilities - in particular, when there are shocks in international capital markets. These shocks have been well recognized in the literature, and Itskhoki and Mukhin (2017) have shown that they are prime candidates to explain a range of puzzles in the economics of exchange rates. We begin by showing that these shocks break the "divine coincidence" and make sterilized intervention a valuable addition to the central bank's policy toolkit. We then show that under discretionary policies, the availability of FX intervention helps reduce the "stabilization bias" associated with the central bank's lack of commitment (Clarida, Gali and Gertler (1999)), where the benefit depends on the degree of openness of the economy. Finally, we show how the availability of FX intervention as policy instrument can reduce the zone of equilibrium indeterminacy (which we interpret as the zone where speculative attacks are possible), thereby contributing to stability and to the credibility of inflation targeting.

Our contribution to the existing literature is threefold. First, we propose a simple model of FX intervention in a New Keynesian Model where sterilized intervention is effective because domestic and foreign investors do not internalize risk premia in the same way (domestic investors rationally expect a bail-out, whereas foreign investors rationally expect a bail-in),

\footnotetext{
${ }^{5}$ Of course, similar stories could be told of central banks that attempted to limit depreciation using FX intervention and eventually had to raise rates. In fact, most central banks have followed such strategies in the major currency crises — e.g. Mexico in 1994; Thailand in 1997; Brazil in 1998; Russia in 1998; etc — albeit with limited success.
} 
thus breaking the uncovered interset parity.

Second, we derive closed-form solutions for the optimal policy of the central bank, under discretion. Our results show that FX intervention can "lean against the wind" and can offset changes in the risk appetite of foreign investors. However, since FX intervention carries welfare costs (because it affects the international asset position of the economy), the central bank only partially offsets shocks to risk appetite. We also show that the welfare benefits of using FX intervention (in addition to interest rate policy) are sizable, at around 0.4 percent of permanent consumption for a standard calibration of the model. The benefits of using FX intervention are null for fully closed economies or for economies where all goods are imported, but they are maximal when two thirds of the consumption basket is imported.

Our third contribution is to show the importance of the financial accelerator for equilibrium indeterminacy, and to highlight that FX intervention can play a useful rule to limit the risk of self-fulfilling, "expectational", bubbles in the exchange rate. We show in particular that central banks that are more willing to use the two instruments they have at hand (FX intervention and conventional interest rate policy) are less likely to face risks of equilibrium indeterminacy.

Our paper is related to the literature on third generation speculative attacks and sudden stops (Krugman (1999); Aghion, Bacchetta and Banerjee (2000); Mendoza (2010)), since we show how financial frictions increase the welfare costs from capital flow volatility as well as the risk of equilibrium indeterminacy. However, the New Keynesian modeling strategy we adopt makes our paper closest to Farhi and Werning (2014), who show how capital controls are useful instruments in economies hit by shocks to capital flows, and to Cavallino (2016), who includes Gabaix and Maggiori (2015)'s microfoundation of FX intervention in a New Keynesian Model solved under commitment.

The paper is organized as follows. Section II discusses the relevant literature. Section III presents the open economy model, in particular the mechanics of FX intervention, as well as a log-linearized version of the model. Section IV describes optimal stabilization policy following shocks to risk appetite in international capital markets, and explains how the use of foreign exchange intervention can help reduce the volatility of the economy. Section V shows that central banks worried about self-fulfilling currency movements should be willing to use both interest rate policy and FX intervention. Section VI provides some concluding remarks.

\section{RELATED LITERATURE}

There is a large empirical literature on the effectiveness of intervention and its channels of transmission, but it is beyond the scope of this paper to review it here. ${ }^{6}$ The recent literature that uses intraday data has been in general supportive of the effect of intervention on the

\footnotetext{
${ }^{6}$ Surveys include Sarno and Taylor (2001) and Neely (2005). Disyatat and Galati (2007) and Menkhoff (2013) are more recent surveys that focus on emerging markets.
} 
exchange rate, at least in the short-term (Melvin et al (2009), Dominguez (2006)), although the significance of intervention is likely to depend on the communication policy of the central bank. For instance, Dominguez et al. (2013) find that irregular, discretionary, interventions had no impact, whereas regular sales of reserves did. Although some of the empirical literature findings are consistent with the theoretical prior that the portfolio balance channel is likely to be most relevant for emerging markets, where the domestic bond markets are smaller than for major industrial countries (Ghosh (1992); Disyatat and Galati (2007)), Dominguez and Frankel (2005) find that the portfolio channel has been significant even for the US and Germany.

Macroeconomic models have usually assumed that the portfolio balance channel is operative, following on the tradition of Kouri (1976) and Branson and Henderson (1985), and to some extent because modeling the other channels (credibility channel and market micro-structure channel) would involve departing significantly from the standard macro framework. Most of the literature has simply assumed some form of financial frictions that make imperfect asset substitutability hold. This is how Schmitt-Grohe and Uribe (2003)) close a linearized open economy model, for instance. Blanchard, Giavazzi and Sa (2005) also assumes that the risk premium is as a function of the share of different currencies in the US investor portfolio, and Benes et al. (2015) include sterilized intervention in a new Keynesian model assuming the portfolio balance channel is working.

Critiques of this approach, in particular Backus and Kehoe (1989), have noted that sterilized intervention would have no effect on the risk premium if it has no fiscal implications beyond the currency composition of debt, even taking into account imperfect asset substitutability. This argument had a strong influence on the literature, contributing to the smaller role of FX intervention in open economy macro models (Blanchard et al. (2005)). However, there are several theoretical reasons why FX intervention could nonetheless matter. Kumhof (2010) noted that argument of Backus and Kehoe (1989) relies on the assumption that any policy is available, whereas in practice fiscal policy tends to either be exogenous or to follow rules. Gabaix and Maggiori (2015) explicitly model imperfect international financial intermediation and show how FX intervention that changes the balance sheet of financial intermediaries is effective. Cavallino (2016) integrates this framework in a New Keynesian open economy model to discuss the benefits of using FX intervention under commitment. Since our paper's contribution is on the dynamic implication of FX intervention for monetary theory, rather than on its finance micro-foundation, we stick to the simpler macroeconomic tradition of Branson and Henderson (1985) and Blanchard et al. (2005), and do not further analyze the foundation of the portfolio balance channel.

The existence of a risk premium is not, however, sufficient to ensure that sterilized intervention is effective or needed. As in Gabaix and Maggiori (2015) and Cavallino (2016), we also postulate the presence of financial frictions; this allows us to model deviations from the divine coincidence and from the UIP. To break the divine coincidence, we assume that exogenous shocks to foreigners' risk appetite (the shocks analyzed by Itskhoki and Mukhin (2017) and which could be proxied by movements of the VIX index) change the cost of borrowing of the Home country. These shocks drive a wedge in the Backus-Smith condition, i.e., a wedge between the consumption plans of Home households and Foreign households 
(e.g., a higher risk premium lowers consumption at Home) and such volatility reduces welfare. FX intervention can mitigate this wedge in our model if it affects the discount rate of Home households and Foreign households differently. Sterilized intervention is not a perfect instrument to offset shocks to the foreign demand for bonds, however, because the use of FX intervention is limited by a budget constraint.

Our paper focuses on the role of FX intervention under discretionary policy. In the standard open economy New Keynesian Model, 'conventional' monetary policy (which we will also call 'interest rate policy') is sufficient to guarantee the stability of the economy because: (i) the two objectives of stable inflation and zero output gap coincide; and (ii) because equilibrium uniqueness is ensured under optimal policy. We discuss the role of FX intervention in cases where either (i) or (ii) is not guaranteed.

The first such case is the occurrence of exogenous shocks that affect the economy's dynamics and that cannot be perfectly offset with conventional monetary policy, for instance by choosing a nominal interest rate such that the real interest rate is equal to the natural rate of interest. ${ }^{7}$ These shocks are often represented as additive factors in the Phillips curve ('cost-push shocks'). We show in this paper that shocks to the risk appetite of foreign investors ("VIX shocks") distort domestic consumption and cannot be fully offset with conventional monetary policy. FX intervention is useful because it allows the central bank to target a level of domestic consumption and get a second handle on macroeconomic dynamics, thus improving the credibility of the central bank's inflation targeting regime. We show that the discretionary bias (Clarida et al. (1999)) is mitigated, and that the welfare losses due to the shock to risk appetite are lowered, through the use of FX intervention.

The second case in which FX intervention is useful is when there is a risk of self-fulfilling currency movements. In the standard open economy New Keynesian Model, equilibrium determinacy is guaranteed even under discretionary policy (Gali (2008)). But in open economy models that incorporate financial frictions (for instance, the effect of the exchange rate on balance sheets and borrowing costs), multiple equilibria are possible (see Aghion et al. (2000) and Aghion, Bacchetta and Banerjee (2004), who follow the tradition of third-generation models of speculative attacks, as in Obstfeld (1986) and Krugman (1999)). Surico (2008) also showed that when the cost channel of monetary policy - a form of financial friction - is present, monetary policy in the absence of a commitment technology may not guarantee determinacy. Accordingly, in this paper, we also investigate the importance of FX intervention in reducing this risk of indeterminacy.

Our paper is closest to that of Farhi and Werning (2014) and of Cavallino (2016), although both papers focus on optimal policy under commitment whereas we focus on optimal discretionary policy. Farhi and Werning (2014) develop a New Keynesian open economy model where the Home country is affected by risk premium shocks but whose central bank can use capital controls as well as monetary policy to stabilize output and inflation. Cavallino (2016) develops a similar model, but integrates the financial intermediary of Gabaix and

\footnotetext{
${ }^{7}$ The natural rate of interest rate is the rate that would prevail for in the equilibrium with flexible prices.
} 
Maggiori (2015) to model the effect of FX intervention. A main difference with our paper is that we focus on discretionary policy; this also allows us to find closed-form solutions which are more easily interpretable.

Although our paper is specifically interested in FX intervention, other instruments may be available for central banks who seek to influence economic activity and the exchange rate. These include quantitative easing, macro-prudential policy, capital controls, although in practice FX intervention is the second most commonly used instrument after the policy interest rate (at least for emerging market economies' central banks; see Ghosh, Ostry and Qureshi (2017)). This paper is thus related to the literature on second instruments, for instance Farhi and Werning (2012), which discusses the role of capital controls in models with shocks to international risk premia; Curdia and Woodford (2011), which analyzes the role of quantitative easing in models with frictions in financial intermediation; Woodford (2012), which discusses the role of macroprudential policy in a similar setting, and Alla, Espinoza and Ghosh (2016), which gives general results on the use of second instruments in New Keynesian models.

\section{A SMALL OPEN ECONOMY}

We extend a standard open economy New Keynesian model, adding a financial friction and FX sterilized intervention, which is effective because of a portfolio balance effect. We begin with the optimization problems of the representative household and of the representative firm before discussing central bank policy.

\section{A. Households}

There is a continuum of countries indexed by $i \in[0,1]$ but we focus on a single country, called Home, and denoted by the subscript $H$. In each country, the representative household's utility function is:

$$
U\left(C_{t}, N_{t}\right)=\sum_{t=0}^{\infty} \beta^{t}\left[\frac{C_{t}^{1-\sigma}}{1-\sigma}-\frac{N_{t}^{1+\phi}}{1+\phi}\right],
$$

where $N_{t}$ is the quantity of labor supplied and $C_{t}$ is aggregate consumption at time $t$ defined as:

$$
C_{t}=\left[(1-\alpha)^{\frac{1}{\eta}} C_{H, t}^{\frac{\eta-1}{\eta}}+\alpha^{\frac{1}{\eta}} C_{F, t}^{\frac{\eta-1}{\eta}}\right]^{\frac{\eta}{\eta-1}} .
$$

$\eta$ denotes the elasticity of substitution between domestic and foreign goods; $\alpha$ is the openness coefficient that parameterizes the share in aggregate consumption of domestic and foreign consumption $C_{H, t}$ and $C_{F, t}$, respectively defined by:

$$
C_{H, t}=\left(\int_{0}^{1} C_{H, t}(j)^{\frac{\varepsilon-1}{\varepsilon}} d j\right)^{\frac{\varepsilon}{\varepsilon-1}}, \quad C_{F, t}=\left(\int_{0}^{1} C_{i, t}^{\frac{\gamma-1}{\gamma}} d i\right)^{\frac{\gamma}{\gamma-1}}
$$


where $j \in[0,1]$ is the index of individual good variety produced domestically, $\varepsilon$ is the elasticity of substitution between domestic goods, $\gamma$ is the elasticity of substitution between foreign goods, and $C_{i, t}$ is the consumption basket imported from country $i$, aggregated across products indexed by $k: C_{i, t}=\left(\int_{0}^{1} C_{i, t}(k)^{\frac{\varepsilon-1}{\varepsilon}} d k\right)^{\frac{\varepsilon}{\varepsilon-1}}$.

The openness parameter $\alpha$ is a measure of home bias: when $\alpha \rightarrow 0$, the share of foreign goods in domestic consumption reaches 0 and the economy can be considered closed. Conversely, when $\alpha \rightarrow 1$, the economy is fully open and since the country's size is infinitesimally small, the share of domestic goods in Home consumption is 0 . The corresponding Consumer Price Index (CPI), domestic Producer Price Index (PPI) and Imported Price Index (IPI) are :

$P_{t}=\left[(1-\alpha)\left(P_{H, t}\right)^{1-\eta}+\alpha P_{F, t}^{1-\eta}\right]^{\frac{1}{1-\eta}}, P_{H, t}=\left[\int_{0}^{1} P_{H, t}(j)^{1-\varepsilon} d j\right]^{\frac{1}{1-\varepsilon}}, P_{F, t}=\left[\int_{0}^{1} P_{i, t}^{1-\gamma} d i\right]^{\frac{1}{1-\gamma}}$.

Domestic households can borrow and lend using risk-free domestic assets. However, we assume that domestic households can only use domestic bonds, contrary to foreign investors who can buy either domestic or foreign bonds (for more details, see Section III.C). The portfolio of the domestic representative household is then made of $D_{t-1}^{h}$ units of domestic bonds and $S_{t-1}^{b}$ units of sterilization bonds sold by the central bank in period $t-1$, both of which pay the home interest rate $i_{t-1}$.

Thus, the (domestic) representative household's problem is to maximize (1) subject to the sequence of budget constraints, for each period $t$ :

$$
\begin{aligned}
{\left[\int_{0}^{1} P_{H, t}^{i}(j) C_{H, t}(j) d j+\int_{0}^{1} \int_{0}^{1} P_{i, t}(k) C_{i, t}(k) d k d i\right]+D_{t}^{h}+S_{t}^{b}+T_{t}^{f i n} } \\
\leq\left(1+i_{t-1}\right)\left(D_{t-1}^{h}+S_{t-1}^{b}\right)+W_{t} N_{t}+\Pi_{t}+T_{t}^{f i r m}+T_{t}^{g o v}
\end{aligned}
$$

where all the variables, which we will describe now, are expressed in domestic currency. $W_{t}$, $\Pi_{t}, T_{t}^{\text {firm }}$ and $T_{t}^{g o v}$ are respectively the nominal wage, profits and lump-sum transfers from the firms and the government. $\Pi_{t}, T_{t}^{\text {firm }}$ and $T_{t}^{\text {gov }}$ are rebated to the representative household. $T_{t}^{f i n}$ is a lump sum tax imposed to households to finance the domestic investors' bail-out when the government defaults (see Section III.C for details about the effect of FX intervention).

\section{B. Firms}

A typical firm $j$ in the domestic economy produces a differentiated good (also indexed by $j$ ) under monopolistic competition with a linear technology using labor as unique input:

$$
Y_{t}(j)=A_{H} N_{t}(j)
$$


where $A_{H}$ is (domestic) labor productivity (which is assumed to be constant in this paper).

A simplified financial accelerator for domestic firms is included in the model: at the beginning of each period, firms must borrow a fixed fraction $\mu \in[0,1]$ of the nominal value of output $P_{H, t}(j) Y_{t}(j)$ they intend to produce. This cost captures working capital requirements at the beginning of the period, used to pay for labor costs or cover other liquidity requirements.

These short-term loans require repayment at the end of each period, after production takes place. Firms thus deduct from their profits the interest costs of working capital requirements, which are charged at the current interest rate $i_{t}$ by the domestic investor (and thus are paid as a lump-sum transfer to the representative household). The financial friction has no direct impact on the country's aggregate wealth since this interest cost is charged domestically, but it is worth noting that since the UIP holds (see below), the cost charged to firms is affected by expected exchange rate movements and by the risk premium. In particular, an expected depreciation of the exchange rate leads to a higher domestic interest rate and higher marginal costs.

The price-setting behaviour of firms follows Gali and Monacelli (2005) in assuming Calvo pricing and that the Law of One Price holds. At each date $t \geq 0$, a randomly selected fraction $1-\delta$ of firms is able to reset prices. Firm $j$ chooses its price $P_{H, t}(j)$ by maximizing profits, i.e. by solving the maximization problem:

$\max _{P_{H, t}(j)} \sum_{k=0}^{\infty} \delta^{k}\left(\prod_{h=1}^{k} \frac{1}{1+i_{t+h}}\right)\left[P_{H, t}(j) Y_{t+k \mid t}(j)-P_{H, t} M C_{t} Y_{t+k \mid t}(j)-\mu P_{H, t}(j) Y_{t+k \mid t}(j) i_{t+k}\right]$

where:

- $Y_{t+k \mid t}(j) \equiv\left(\frac{P_{H, t}(j)}{P_{H, t+k}}\right)^{-\varepsilon} Y_{t+k}$ is the demand for firm's $j$ good at date $t+k$ if prices were reset for the last time at date $t$;

- $M C_{t} \equiv \frac{1+\tau}{A_{H}} \frac{W_{t}}{P_{H, t}}$ is the real marginal cost deflated by home PPI ${ }^{8}$

- $\mu P_{H, t}(j) Y_{t+k \mid t}(j) i_{t+k}$ represents the working capital cost bore by firms.

The solution to this problem is presented in Appendix I.

\section{Foreign investors}

Foreign investors can invest in Home bonds, and changes in their demand for these bonds are an important source of shocks. Indeed, most discussions about the use of FX intervention in developing countries are related to the desire to smooth the impact of sudden capital inflows

\footnotetext{
${ }^{8} \mathrm{We}$ allow for a constant labor tax $\tau$ to make the steady state efficient.
} 
and outflows that result from fluctuations in foreign investors' perception of risk. To contribute to this discussion, we assume, as in Farhi and Werning (2014), that the Home country is hit by a "VIX" shock, i.e. an exogenous shock to risk appetite $\Xi_{t}$ that captures changes in foreign investors' interest for local bonds (Itskhoki and Mukhin (2017) show that these shocks are crucial determinants of exchange rates). ${ }^{9}$ It is possible to model the sources of this shock in more detail, as is done in Gabaix and Maggiori (2015) by assuming imperfect international financial intermediation and modeling the behavior of financial intermediaries, but we abstract from these issues since they are inessential to our argument.

The shock $\Xi_{t}$ is defined such that the gross return perceived by foreign investors in domestic currency $\frac{1+i_{t}}{\Xi_{t}}$ differs from the gross interest rate paid by the central bank, $1+i_{t}$ (see also UIP in equation (4) below). This shock allows us to analyze either the impact of capital flow surges (negative risk premium shock $\Xi_{t}$ ) or of sudden stops (positive risk premium shock $\Xi_{t}$ ). For a given exchange rate and foreign interest rate, a positive risk premium shock is thus akin to an increase in the domestic interest rate, but one affecting only domestic households. A positive risk premium shock can also be interpreted as a negative shock to domestic consumption: since the interest rate faced by domestic households suddenly increases, domestic consumption falls (this also leads to a trade surplus). Because this shock lowers domestic consumption, it reduces the required real wage (since labor supply is stimulated when consumption is low), even when there is no output gap. Thus, this shock breaks the divine coincidence, which is why it calls for a second policy instrument that would complement monetary policy. We now explain why FX intervention is particularly suitable as the second instrument.

\section{The central bank, sterilized interventions and the government}

\section{The central bank}

In each period, the central bank chooses the interest rate and performs sterilized foreign exchange intervention, offsetting any increase in reserves $\left(R_{i, t}\right.$ denotes the Home central bank's holdings of currency $i$, valued in local currency using the exchange rate $E_{i, t}$ ) by issuing sterilization bonds $S_{t}^{b}$, so as to keep the money supply constant and the policy interest rate unchanged:

$$
\int_{0}^{1} E_{i, t} R_{i, t} d i-\int_{0}^{1} E_{i, t}\left(1+i_{t-1}^{i}\right) \Xi_{t-1} R_{i, t-1} d i=S_{t}^{b}-\left(1+i_{t-1}\right) S_{t-1}^{b}
$$

This intervention implies a change in the stock of public debt held by the private sector, and thus an increase in the risk premium $\Psi_{t}$ on domestic bonds because of a portfolio balance channel effect. We assume that the risk-premium is a function of the level of reserves, and thus of the level of (general) government debt held by the private sector: $\Psi_{t}=\left(\left(\int_{0}^{1} E_{i, t} R_{i, t} d i\right) / \bar{R}\right)^{\varphi}$, where $\varphi$ is the elasticity of the risk premium to reserves and $\bar{R}$ is the equilibrium level of reserves for which there is no risk premium. This formulation is akin

\footnotetext{
${ }^{9} \Xi_{t}$ could also be thought of as capturing time-varying and country-specific borrowing constraints.
} 
to Schmitt-Grohe and Uribe (2003)'s model of the risk premium (see also Blanchard et al. (2005) and Benes et al. (2015)). ${ }^{10}$

As will be shown in Section III.E, an exogenous shock to foreigners' risk appetite and thus to demand for Home bonds drives a wedge in the Backus-Smith condition, i.e., a wedge between the consumption plans of the Home households and of Foreign household, and such volatility reduces welfare. FX intervention can mitigate this wedge if it affects the discount rate of Home households and Foreign households differently. To achieve this, we assume that Home households cannot borrow from or invest abroad ${ }^{11}$ (this breaks their ability to run carry trades) and that FX intervention is perceived differently by foreign investors and domestic investors, as we explain now.

\section{Foreign investors' view of FX intervention}

We assume that foreign investors, who are sophisticated agents used to the risks of debt restructuring, internalize that the risk premium $\Psi_{t}$ compensates exactly, in an actuarially fair sense, for a partial default they will suffer-i.e., foreign investors rationally expect to be bailed in. Thus, for foreign investors from country $i$ (e.g. in the US), the rate of return on Home bonds, taking into account the risk premium but also the default rate, should be equal to the rate of return in the US. As a result, since we also have to take into account the shock to preferences $\Xi_{t}$, for a foreign investors living in country $i$, the UIP is:

$$
\frac{1+i_{t}}{\Psi_{t} \Xi_{t}}=\left(1+i_{t}^{i}\right) \frac{E_{i, t+1}}{E_{i, t}}
$$

\section{Domestic households' view of FX intervention}

On the other hand, we assume that domestic households correctly anticipate they will be bailed out following the domestic government's partial default. Thus, domestic households do perceive a higher rate of return on domestic bonds, and thus face a higher interest rate in their intertemporal consumption Euler equation (by the value of the risk premium).

A lump sum tax $T_{t}^{f i n}$ is imposed to households to finance the bailout of domestic bond holders. Since our model does not feature uncertainty, this lump-sum tax is paid at each

\footnotetext{
${ }^{10}$ In Gabaix and Maggiori (2015), the effectiveness of FX intervention (captured by our elasticity $\varphi$ ) would depend on the importance of the friction affecting the international financial intermediaries, and on the relation of the size of intervention to the size of the intermediaries' balance sheet (which would be proxied by our parameter $\bar{R})$.

${ }^{11}$ In reality, households in small open economies do invest part of their net wealth abroad, but they do not run carry trade, i.e., borrow in local currency at a high interest rate to invest abroad at a low rate, even though the local exchange rate may be depreciating faster than what the UIP would imply. The reasons for limited carry trade from emerging economies may be due to liquidity constraints, short-termism (since future capital gains are offset by today's losses in interest income), or regulatory constraints on FX position. Such regulatory constraints certainly also prevent households to borrow significant amounts in foreign currency to invest at home.
} 
period, and is equal to the risk premium paid on the total amount of domestic bonds held by domestic households:

$$
T_{t}^{f i n}=\frac{\Psi_{t}-1}{\Psi_{t}}\left(D_{t}^{h}+S_{t}^{b}\right)
$$

Although the risk-premium affects the Euler equation, the lump sum tax to finance it does not. Thus, foreign exchange interventions affect the interest rate faced by foreign investors, but not the one faced by domestic households. Foreign exchange interventions then introduce a wedge between the domestic households' and the foreign households' consumption plans. As a result, FX intervention will distort domestic consumption, but without changing foreign demand and exports.

\section{Why is FX intervention useful?}

The "endogenous" risk premium $\Psi_{t}$ allows the central bank to influence the exchange rate for a given policy interest rate and a given "VIX" shock to risk appetite $\Xi_{t} \cdot{ }^{12} \mathrm{~A}$ positive shock to $\Xi_{t}$, indicating a lower appetite from foreign investors for domestic bonds, implies that foreign investors have to be compensated when buying domestic bonds. The Home central bank has three possible strategies:

- to accept a large instantaneous currency depreciation (and a subsequent appreciation);

- to increase the interest rate;

- to sell foreign exchange reserves to lower the risk premium $\Psi_{t},{ }^{13}$ and thus appreciate its currency.

As explained earlier, the "VIX" shock affects domestic consumption, and as a result it affects both the IS curve and the Phillips curve (from the labor supply side, wages are a function of consumption). The interest rate, however, is mostly an instrument to manage demand (i.e. the IS curve). Note also that the more open the economy, the more distinct are domestic consumption and domestic output, and thus the more penalizing it is to accept exchange rate movements or to use monetary policy to respond to a shock to domestic consumption. FX intervention has the advantage of targeting domestic consumption directly and is thus a better instrument to offset shocks to the risk premium.

Absent FX intervention, domestic consumption would suffer because of the VIX shock, and because optimal policy would suggest a combination of monetary policy tightening and currency depreciation (see Section IV.B for a numerical example) that would affect the totality of domestic output and lead to greater economic volatility. By lowering its reserves, the central bank can moderate the impact of the shock on domestic consumption.

\footnotetext{
${ }^{12}$ Reserves may be insufficient to offset large expected depreciations, but we do not discuss this possibility here.

${ }^{13}$ For simplicity, we assume that only the Home central bank uses FX intervention. This assumption will be natural in our context of a small open economy taking the rest of the world as given.
} 
Empirical studies have confirmed that central banks can indeed protect consumption by reducing reserves (Jeanne and Ranciere (2011)). Such interventions reduce the required depreciation of the exchange rate, limit interest rate increases, and thus lower macroeconomic volatility.

\section{The government}

The central government's revenues are its tax receipts $\left(\tau W_{t} N_{t}\right)$. In addition, the government sells bonds to domestic investors (the representative household, who holds $D_{t}^{h}$ bonds) and to foreign investors (who hold $D_{t}^{f}$ bonds). At each period, the government defaults partially on bonds held by domestic households thus receiving as debt relief $T_{t}^{f i n}=\frac{\Psi_{t}-1}{\Psi_{t}}\left(D_{t}^{h}+S_{t}^{b}\right)$. Finally, the government rebates to households the labor tax revenues through a lump-sum transfer: $T_{t}^{g o v}=\tau W_{t} N_{t}$. The government budget constraint is then:

$$
\frac{1+i_{t-1}}{\Psi_{t-1}} D_{t}^{f}+\left(1+i_{t-1}\right)\left(D_{t}^{h}+S_{t}^{b}\right)+T_{t}^{g o v} \leq D_{t+1}^{f}+D_{t+1}^{h}+\tau W_{t} N_{t}+T_{t}^{f i n}
$$

\section{Exchange rates and the terms of trade}

Since the Law of One Price holds, we have:

$$
P_{F, t}=E_{t} P_{t}^{*}
$$

where $P_{t}^{*}=\left[\int_{0}^{1} P_{i, t}^{i}{ }^{1-\gamma} d i\right]^{\frac{1}{1-\gamma}}$ is the world price index, and $P_{i, t}^{i}$ is the country i's domestic PPI in its own currency. The above equation then defines the effective nominal exchange rate $E_{t}$.

Finally, the terms of trade $S_{t}$ and the real exchange rate $Q_{t}$ of Home are defined as:

$$
S_{t}=\frac{P_{F, t}}{P_{H, t}}=\frac{E_{t} P_{t}^{*}}{P_{H, t}} \quad Q_{t}=\frac{P_{F, t}}{P_{t}}=\frac{E_{t} P_{t}^{*}}{P_{t}} .
$$

\section{E. Equilibrium Conditions}

We now consider the situation in which Home takes the rest of the world as given and is the only country that intervenes in the FX market. The rest of the world is exogenous and all foreign countries are identical. Foreign variables are denoted with stars.

The supply side equations include: 
- the optimal labor-leisure decision by households for a given CPI and nominal wage:

$$
C_{t}^{\sigma} N_{t}^{\phi}=\frac{W_{t}}{P_{t}}
$$

- the Calvo price setting optimal conditions which are complex in the non-linearized setup and presented in the Appendix I

The demand side equations are:

- the Euler equation for domestic households

$$
1+i_{t}=\beta^{-1}\left(\frac{C_{t+1}}{C_{t}}\right)^{\sigma} \frac{P_{t+1}}{P_{t}}
$$

We write current consumption as a function of foreign consumption $C_{t}^{*}$ and the relative Pareto weight of Home in world consumption $\Theta_{t}$ :

$$
C_{t}=\Theta_{t} C_{t}^{*} Q_{t}^{1 / \sigma} .
$$

This equation will be called the Backus-Smith condition, although it is an abuse of language since it is the definition of $\Theta_{t}$ in this model.

- the no-arbitrage condition (for a foreign household) between home and foreign bonds gives the law of motion of $\Theta_{t}{ }^{14}$ :

$$
\left(\frac{\Theta_{t+1}}{\Theta_{t}}\right)^{\sigma}=\frac{1+i_{t}}{1+i_{t}^{*}} \frac{E_{t}}{E_{t+1}}=\Psi_{t} \Xi_{t}
$$

where the risk premia $\Psi_{t}$ and $\Xi_{t}$ have already been introduced. The logarithm of $\Theta_{t}$ appears to follow an autoregressive process. $\Theta_{t}$ can thus be interpreted as a cumulative risk premium. Together with equation (6), equation (7) shows how exogenous shocks to foreign investors' risk appetite and FX intervention affect domestic consumption, since they introduce a wedge between the domestic and the foreign paths of consumption. Since monetary policy has symmetric effects on domestic and foreign consumption, it is not the ideal instrument to offset such shocks. On the contrary, FX intervention also moves domestic consumption, and is thus better suited as a second policy instrument in response to such shocks to risk appetite.

${ }^{14}$ Using the definition of $\Theta_{t}$, we have $\left(\frac{\Theta_{t+1}}{\Theta_{t}}\right)^{\sigma}=\left(\frac{C_{t+1}}{C_{t}}\right)^{\sigma} \frac{P_{t+1}}{P_{t}}\left({\frac{C_{t}^{*}}{C_{t}+1}}^{*}\right)^{\sigma} \frac{E_{t} P_{t}^{*}}{E_{t+1} P_{t+1}^{*}}$. The Euler equations for domestic and foreign households give: $1+i_{t}=\beta^{-1}\left(\frac{C_{t+1}}{C_{t}}\right)^{\sigma} \frac{P_{t+1}}{P_{t}}$ and $1+i_{t}^{*}=\beta^{-1}\left(\frac{C_{t+1}^{*}}{C_{t}^{*}}\right)^{\sigma} \frac{P_{t+1}^{*}}{P_{t}^{*}}$. Dividing the domestic Euler equation by the foreign Euler equation, and using the first equation above, we find the law of motion of $\Theta_{t}$, i.e., equation (7). 
In addition, the market clearing conditions are:

- for the goods market:

$$
Y_{t}=(1-\alpha)\left(\frac{Q_{t}}{S_{t}}\right)^{-\eta} C_{t}+\alpha S_{t}^{\gamma} C_{t}^{*}
$$

- for the labor market:

$$
N_{t}=\frac{Y_{t}}{A_{H}} \Delta_{t}
$$

where $\Delta_{t}$ is the index of price dispersion defined by

$$
\Delta_{t}=\int_{0}^{1}\left(\frac{P_{H, t}(j)}{P_{H, t}}\right)^{-\varepsilon} d j
$$

and where the relation between the terms of trade and the real exchange rate is

$$
Q_{t}=\left[(1-\alpha) S_{t}^{\eta-1}+\alpha\right]^{\frac{1}{\eta-1}}
$$

The country's budget constraint at date $t$, which is derived by adding the budget constraints of the households (equation (2)), of the central bank (equation (3)) and of the government (equation (5)), is (see Appendix II): ${ }^{15}$

$$
N F A_{t}=-\frac{1}{P_{F, t} C_{t}^{* \sigma}} N X_{t}+\beta \Xi_{t}^{-1} N F A_{t+1}
$$

where the country net foreign asset $\operatorname{position}^{16}$ and trade balance are respectively:

$$
N F A_{t}=\frac{\left(1+i_{t-1}^{*}\right) \Xi_{t-1} E_{t}}{P_{F, t} C_{t}^{* \sigma}}\left[R_{t}^{*}-\frac{D_{t}^{f}}{E_{t-1}}\right], \quad N X_{t}=P_{H, t} Y_{t}-P_{t} C_{t}
$$

Finally, we get the intertemporal budget constraint by taking $N F A_{0}=0$, solving forward equation (11), and imposing the transversality condition:

$$
\sum_{t=0}^{\infty} \beta^{t}\left(\prod_{s=0}^{t-1} \Xi_{s}\right)^{-1} C_{t}^{*-\sigma}\left[\frac{Y_{t}}{S_{t}}-\frac{C_{t}}{Q_{t}}\right] \geq 0
$$

\footnotetext{
${ }^{15}$ Since firms' borrowing is domestic, interest payments are collected by domestic investors and thus they do not affect the country's budget constraint at date $t$.

${ }^{16} \mathrm{We}$ normalize the net foreign asset position by the foreign consumption and take the foreign price at home $P_{F, t}$ as the numeraire.
} 


\section{F. The log-linearized framework}

Following Gali and Monacelli (2005) and Farhi and Werning (2014), our analytical results are derived for the log-linearized model using the Cole-Obstfeld parametrization, where $\sigma=\eta=\gamma=1$ (Cole and Obstfeld (1991)). A lower case variable denotes the log-deviation from the deterministic steady-state of the variable. ${ }^{17}$

To disentangle the effects of the two risk premia, we decompose the Pareto weight $\theta_{t}$, i.e., the wedge between domestic and foreign consumption, as follows:

$$
\theta_{t}=\hat{\theta}_{t}+\bar{\theta}_{t} \quad \text { where }
$$

- $\bar{\theta}_{t}$ is the distortion to consumption resulting from the "VIX" shock to risk appetite $\xi_{t}$;

- $\hat{\theta}_{t}$ the the distortion to consumption resulting from the FX intervention's risk premium $\psi_{t}$.

\section{Demand side}

The log-linearization of the goods market clearing condition gives

$$
y_{t}=(1-\alpha)\left[-\left(q_{t}-s_{t}\right)+c_{t}\right]+\alpha s_{t}=(1-\alpha) \theta_{t}+s_{t}
$$

since $c_{t}^{*}=0$ and thus $q_{t}=c_{t}-\theta_{t}$ (from the Backus-Smith condition). Thus $\theta_{t}$ has an effect on aggregate demand (and thus on Home prices and the terms of trade; this is the demand channel of risk premia-see below for the supply channel), but it has a smaller effect on $y_{t}$ than on $c_{t}$ if $q_{t}$ and $s_{t}$ are small, i.e. in the short run where prices are sticky (since $\left.c_{t}=\theta_{t}+q_{t}\right)$. Overall, the demand side can be represented by the dynamic Investment Saving (IS) equation

$$
\begin{aligned}
y_{t} & =y_{t+1}^{e}-\left(i_{t}-\pi_{H, t+1}^{e}-\rho\right)+\alpha\left(\psi_{t}+\xi_{t}\right) \\
& =y_{t+1}^{e}-\left(i_{t}^{*}-\pi_{H, t+1}^{e}-\rho\right)+e_{t}-e_{t+1}^{e}-(1-\alpha)\left(\psi_{t}+\xi_{t}\right)
\end{aligned}
$$

Equation (14) shows that for a given exchange rate and given expectations, higher risk premia, which increase the domestic interest rate, hurt consumption and thus output (the effect is proportional to $1-\alpha$, the weight of domestic consumption in output). In addition, the UIP is:

$$
e_{t}=e_{t+1}^{e}-\left(i_{t}-i_{t}^{*}\right)+\psi_{t}+\xi_{t}
$$

Given exchange rate expectations and monetary policy decisions, a positive risk premium, either due to a preference shock or to an increase in the level of reserves, triggers a depreciation of the local currency.

\footnotetext{
${ }^{17}$ Note that the model and the loss function are presented differently from that in Farhi and Werning (2014), who present variables in deviation from the natural allocation, whereas we express them in deviation from the deterministic steady state.
} 


\section{Supply side}

The supply side consists of the New-Keynesian Phillips Curve:

$$
\begin{gathered}
\pi_{H, t}=\beta \pi_{H, t+1}^{e}+\kappa_{y} y_{t}+\kappa_{\theta}\left(\hat{\theta}_{t}+\bar{\theta}_{t}\right)+\kappa_{f}\left(i_{t}-\rho\right) \\
\text { where } \kappa_{y}=\lambda(1+\phi), \quad \kappa_{\theta}=\lambda \alpha, \quad \kappa_{f}=\lambda \mu
\end{gathered}
$$

$\lambda$ captures price flexibility and is increasing in the share of firms that can reset their prices. ${ }^{18}$

The new term $\kappa_{\theta}\left(\hat{\theta}_{t}+\bar{\theta}_{t}\right)$ represents the effect of the risk premium on domestic firms' marginal costs (the supply channel of risk premia). Following a negative risk premium shock, which leads to a positive shock to domestic consumption $\left(\bar{\theta}_{t}>0\right)$, real wages have to be increased in order to maintain labor supply. This is why firms' marginal costs and inflation increase. But FX intervention can "lean against the wind": the central bank can increase the risk premium (by accumulating reserves and selling sterilization bonds), thus increasing the endogenous risk premium and depressing consumption $\left(\hat{\theta}_{t}<0\right)$.

As highlighted in Section III.C, the exogenous risk premium targets specifically domestic consumption and not the whole of domestic output (exports are not affected), and this is what breaks the divine coincidence. This effect is clearly visible in equation (16). It is also worth noting that the effect of the exogenous risk premium on PPI inflation is increasing in the economy's openness $\left(\kappa_{\theta}=\lambda \alpha\right)$ because the more open the economy, the larger the difference between output and consumption (which is the part of output that is independently affected by the risk premium).

Finally, the financial accelerator appears in the Phillips curve (through the term $\kappa_{f}\left(i_{t}-\rho\right)$ ) in a way similar to that of the cost channel of monetary policy (Surico (2008)). Since the UIP holds, the financial accelerator is also $\kappa_{f}\left(i_{t}-\rho\right)=\kappa_{f}\left[e_{t+1}^{e}-e_{t}+i_{t}^{*}-\rho+\theta_{t+1}^{e}-\theta_{t}\right]$. Exchange rate expectations affect firms' marginal costs and can thus have real effects. In Section V, we explore the impact of the financial accelerator on equilibrium determinacy under optimal discretionary policy and discuss the ability of FX intervention to reduce the risk of indeterminacy.

\section{The intertemporal budget constraint}

The intertemporal budget constraint is :

$$
\sum_{t=0}^{\infty} \beta^{t} \hat{\theta}_{t}=0 .
$$

${ }^{18} \lambda=\frac{(1-\delta)(1-\beta \delta)}{\delta}$. As a result, $\lambda \rightarrow \infty$ when prices are fully flexible 
The intertemporal budget constraint requires that the discounted value of the distortions to domestic consumption be zero. When the central bank sells reserves, the risk-premium decreases and domestic consumption increases, thus worsening the trade balance $\left(n x_{t}=-\alpha\left(\bar{\theta}_{t}+\hat{\theta}_{t}\right)\right)$. A larger trade deficit has to be compensated by larger surpluses in the future, which is what this intertemporal budget constraint captures, and this is why it is impossible to use FX intervention to affect the path of consumption permanently. Although our model will be solved under discretionary policy, we assume that the intertemporal budget constraint is taken into account by the central bank, i.e. we assume that policy institutions in the economy are strong enough so that the central bank will value the international position of the country at a constant (shadow) price $^{19}$.

\section{G. Loss function}

The welfare costs due to deviations from the steady state can be expressed using the following welfare loss function (proved in Appendix III, using a second-order approximation):

$$
\frac{1}{2} \sum_{t=0}^{\infty} \beta^{t}\left[\alpha_{\pi} \pi_{H, t}^{2}+y_{t}^{2}+\alpha_{\theta}\left[\hat{\theta}_{t}+\alpha_{\psi} \bar{\theta}_{t}\right]^{2}\right]
$$

where

$$
\alpha_{\pi}=\frac{\varepsilon_{P}}{\lambda_{P}(1+\phi)}, \quad \alpha_{\theta}=\frac{\alpha}{1+\phi}\left(\frac{2-\alpha}{1-\alpha}+1-\alpha\right), \quad \alpha_{\psi}=\frac{1-\alpha}{\frac{2-\alpha}{1-\alpha}+1-\alpha}
$$

The first two terms are familiar - they are identical to those obtained in Gali and Monacelli (2005). The third term captures the direct distortions induced by FX intervention on domestic consumption. Indeed, FX intervention targets specifically domestic consumption, thus it generates additional welfare costs, on top of those related to the distortion of output and the dispersion of relative prices. Sterilized intervention can reallocate domestic demand intertemporally (as do capital controls in Farhi and Werning (2012)). But such reallocation comes at a cost for welfare, expressed as follows:

$$
\alpha_{\theta}\left[\hat{\theta}_{t}+\alpha_{\psi} \bar{\theta}_{t}\right]^{2}=\alpha_{\theta} \underbrace{\hat{\theta}_{t}^{2}}_{\text {cost of external imbalance }}+2 \alpha_{\theta} \alpha_{\psi} \underbrace{\hat{\theta}_{t} \bar{\theta}_{t}}_{\begin{array}{c}
\text { costs of distorting } \\
\text { consumption }
\end{array}}+\text { exogenous terms }
$$

The welfare costs of FX intervention are thus due to:

- the cost of external imbalances:

\footnotetext{
${ }^{19}$ Basu, Ghosh, Ostry and Winant (2017) analyze the time consistent equilibrium when reserves are limited and central bank policy is time inconsistent.
} 
Selling reserves decreases the endogenous risk premium, and therefore increases domestic consumption without changing foreign demand or Home exports. This worsens the trade balance. Such distortion to the trade balance imposes a welfare cost because the intertemporal budget constraint has to hold (the second order approximation of the budget constraint is what is capture by the term $\alpha_{\theta} \hat{\theta}_{t}^{2}$ ); FX intervention can smooth domestic consumption but cannot increase it permanently. We also find that the more open the economy, the more costly it is to distort the trade balance. Indeed, the welfare cost is proportional to $\alpha_{\theta}=\frac{\alpha}{1+\phi}\left(\frac{2-\alpha}{1-\alpha}+1-\alpha\right)$, which is an increasing function of $\alpha$.

- the costs of distorting consumption:

A positive shock to the exogenous risk premium increases the interest rate faced by domestic consumers and decreases domestic consumption. Even keeping output constant, the fall in domestic consumption also leads to a fall in domestic prices (because of Home bias in consumption), which decreases the terms of trade. ${ }^{20} \mathrm{FX}$ intervention has symmetric effects. This means that when FX intervention is used to offset the exogenous risk premium, it is able to stabilize consumption (which has welfare benefits in itself) as well as the terms of trade, which is also worthwhile given the intertemporal budget constraint. The welfare loss of distorting consumption is proportional to $\alpha_{\theta} \alpha_{\psi}=\frac{\alpha(1-\alpha)}{\text {. When the economy is closed }(\alpha \rightarrow 0) \text {, output and } 1+\phi}$ domestic consumption coincide, and there is no cost due to deviations in domestic consumption that is not already captured by the cost of a non-zero output gap. When the economy is fully open $(\alpha \rightarrow 1)$, Home consumption is entirely made of imported goods, and there is no cost in distorting it as this does not affect the terms of trade or consumption. ${ }^{21}$

Finally, we note that contrary to the other elements in the welfare loss function (inflation, output gap, and terms of trade), the cost of external imbalance exists even when the country is fully open. Gali and Monacelli (2005) indeed showed that the welfare losses resulting from distortions in output and inflation go to zero when $\alpha \rightarrow 1$. However, since the cost of external imbalances affect the path of domestic consumption, this cost exists even when the economy is fully open. Because the welfare cost of a non-zero output gap distortion was normalized to 1 , the welfare cost of external imbalances goes to infinity when $\alpha \rightarrow 1$.

\section{Planning problem}

We assume that the authorities are unable to commit to specific future policies (on the interest rate, asset purchases, the deficit, etc). Working in a discretionary setup, as opposed to

\footnotetext{
${ }^{20}$ This effect exists as long as the economy is not fully open, i.e. as long as the share $\alpha$ of domestic goods consumed by domestic households is not zero.

${ }^{21}$ More precisely, as shown by Farhi and Werning (2014), optimal policy with a fully open economy would consist of maximizing the monopoly profits of exporters, but given that under the Cole-Obstfeld parameterization, exporters face a demand with elasticity of 1, the monopoly problem is degenerate. As a result, output should converge to 0 when $\alpha \rightarrow 1$, and distorting consumption does not help with the terms of trade, which is why FX intervention is useless.
} 
the commitment framework analyzed in Farhi and Werning (2014) and in Cavallino (2016), also allows us to derive simple and transparent closed-form formulas. The complete planning problem at date $t$ is thus composed of the objective function; the Phillips curve; the IS equation; the UIP condition; the dynamic relation between the consumption wedge and FX intervention; the intertemporal budget constraint of the country; ${ }^{22}$ and the initial condition for the output gap:

$$
\begin{gathered}
\min _{\pi_{H, t}, y_{t}, i_{t}, \psi_{t}, \hat{\theta}_{t}, e_{t}} \alpha_{\pi} \pi_{H, t}^{2}+y_{t}^{2}+\alpha_{\theta}\left[\hat{\theta}_{t}+\alpha_{\psi} \bar{\theta}_{t}\right]^{2} \text { s.t. } \\
\pi_{H, t}=\beta \pi_{H, t+1}^{e}+\kappa_{y} y_{t}+\kappa_{\theta} \hat{\theta}_{t}+\kappa_{\theta} \bar{\theta}_{t}+\kappa_{f}\left(i_{t}-\rho\right) \\
y_{t}=y_{t+1}^{e}-\left(i_{t}-\pi_{H, t+1}^{e}-\rho\right)+\alpha\left(\psi_{t}+\xi_{t}\right) \\
e_{t}=e_{t+1}^{e}-\left(i_{t}-i_{t}^{*}\right)+\psi_{t}+\xi_{t} \\
\hat{\theta}_{t+1}^{e}=\psi_{t}+\hat{\theta}_{t} \\
\sum_{t=0}^{\infty} \beta^{t} \hat{\theta}_{t}=0 \\
y_{0}=(1-\alpha)\left(\hat{\theta}_{0}+\bar{\theta}_{0}\right)+e_{0}
\end{gathered}
$$

\section{OPTIMAL STABILIZATION POLICY FOLLOWING RISK PREMIUM SHOCKS}

In this section, we describe optimal monetary and FX intervention policies following an exogenous shock. We focus on exogenous risk premium shocks in international capital markets, as introduced in Section III.A. These shocks capture the changes in foreign investors' sentiment that have historically led to volatile episodes of capital inflows (negative risk premium shocks) or capital outflows (positive risk premium shocks). Such "push factors" can be considered to be exogenous to the economy. We show how FX intervention allows the central bank to reduce volatility when confronted with these external shocks.

\section{A. Optimal use of FX intervention following risk premium shocks}

A positive risk premium shock stands for a reduction in foreign investors' appetite for domestic bonds. This shock affects both domestic allocation and welfare (the latter through domestic terms of trade stabilization effect as was explained in Section III.F). Proposition 1 provides a transparent analysis based on closed-form formula that details how FX intervention is optimally used following a risk premium shock. For the sake of clarity, the analytical results are presented in Proposition 1 with the financial accelerator turned off

\footnotetext{
${ }^{22}$ The quadratic approximation of the budget constraint included in the welfare objective does not ensure that this constraint is satisfied; the presence of the intertemporal constraint in the objective function is necessary (due to the microfoundations) but not sufficient to ensure that the constraint is satisfied.
} 
$(\mu=0)$ although the qualitative and quantitative results are similar when the financial accelerator is turned on (see footnote 23 and Section IV.B; on the contrary, our results on indeterminacy in Section $\mathrm{V}$ depend crucially on the size of the financial accelerator).

\section{Proposition 1. Optimal policy following risk premium shocks}

Following an exogenous risk premium shock with autoregressive process $\xi_{t}=\xi_{0} \rho^{t}$, the optimal paths for inflation, output, the endogenous consumption wedge and the endogenous risk premium are: ${ }^{23}$

$$
\begin{aligned}
& \pi_{H, t}=\frac{\kappa_{\theta}\left(1-\alpha_{\psi}\right) \xi_{0}}{1-\rho}\left(\frac{1-\beta}{1-\rho \beta} \frac{1}{D\left(\alpha_{\theta}, 1\right)}-\frac{1}{D\left(\alpha_{\theta}, \rho\right)} \rho^{t}\right)+\frac{\kappa_{\theta}}{\alpha_{\theta} D\left(\alpha_{\theta}, 1\right)} \Gamma \\
& y_{t}=-\alpha_{\pi} \kappa_{y} \pi_{H, t} \\
& \hat{\theta}_{t}=\frac{\xi_{0}}{1-\rho}\left[1-\left(1-\alpha_{\psi}\right) \frac{D(+\infty, \rho)}{D\left(\alpha_{\theta}, \rho\right)}\right]\left(\rho^{t}-\frac{1-\beta}{1-\rho_{\xi} \beta}\right) \\
& \psi_{t}=\xi_{0}\left[\left(1-\alpha_{\psi}\right) \frac{D(+\infty, \rho)}{D\left(\alpha_{\theta}, \rho\right)}-1\right] \rho^{t} \\
& e_{t+1}-e_{t}=i_{t}-i_{t}^{*}-\left(\psi_{t}+\xi_{t}\right) \quad, \text { with } e_{0}=y_{0}-(1-\alpha)\left(\hat{\theta}_{0}+\bar{\theta}_{0}\right)
\end{aligned}
$$

where $^{24}$

$$
D\left(\alpha_{\theta}, \rho_{\xi}\right)=1-\rho_{\xi} \beta+\alpha_{\pi}\left(\kappa_{y}^{2}+\frac{\kappa_{\theta}^{2}}{\alpha_{\theta}}\right)
$$

\section{Proof: See Appendix IV}

A positive risk premium shock decreases domestic consumption (and thus $\theta_{t}$ ) in the short run since it increases the interest rate faced by domestic households. ${ }^{25}$ Such a shock would lower inflation even if output were perfectly stabilized and FX intervention not used because of Home bias in consumption. Optimal monetary policy without FX intervention would consist

\footnotetext{
${ }^{23}$ When the financial accelerator is active (i.e. $\left.\mu \neq 0\right)$ ), the results become: $\pi_{H, t}=\frac{\left(1-\alpha_{\psi}\right) \xi_{0}}{1-\rho_{\xi}}\left[K(1)-K\left(\rho_{\xi}\right) \rho_{\xi}^{t}\right]+\frac{\kappa_{\theta}}{\alpha_{\theta} D(1)} \Gamma ; \quad y_{t}=-X_{y} \pi_{H, t}$ $\hat{\theta}_{t}=\frac{\xi_{0}}{1-\rho_{\xi}}\left[\left(1-\alpha_{\psi}\right) \frac{D^{y}\left(\rho_{\xi}\right)}{D\left(\rho_{\xi}\right)}-1\right]\left(\frac{1-\beta}{1-\rho_{\xi} \beta}-\rho_{\xi}^{t}\right) \quad ; \quad \psi_{t}=\xi_{0}\left[\left(1-\alpha_{\psi}\right) \frac{D^{y}\left(\rho_{\xi}\right)}{D\left(\rho_{\xi}\right)}-1\right] \rho_{\xi}^{t}$ where $\Gamma=\frac{\left(1-\alpha_{\psi}\right) \xi_{0}}{\left(1-\rho_{\xi}\right)\left(1-\frac{\alpha_{\pi} \kappa_{\theta}\left(\kappa_{\theta}-\alpha_{f}\right)}{\alpha_{\theta} D(1)}\right)}\left(\frac{\kappa_{\theta}}{D(1)}-\frac{\kappa_{\theta}-\alpha\left(1-\rho_{\xi}\right) \kappa_{f}}{D\left(\rho_{\xi}\right)} \frac{1-\beta}{1-\rho_{\xi} \beta}-\alpha_{\theta} \frac{\beta\left(1-\rho_{\xi}\right)}{1-\beta \rho_{\xi}}\right)$; $D\left(\rho_{\xi}\right)=1+\alpha_{\pi}\left[\left(\kappa_{y}-\kappa_{f}\right)^{2}+\frac{\left(\kappa_{\theta}-\alpha \kappa_{f}\right)^{2}}{\alpha_{\theta}}\right]-\rho_{\xi}\left\{\beta+\kappa_{f}\left[1-\alpha_{\pi}\left(k_{y}-k_{f}+\frac{\alpha\left(\kappa_{\theta}-\alpha \kappa_{f}\right)}{\alpha_{\theta}}\right)\right]\right\}$ and $D^{y}\left(\rho_{\xi}\right)=1+\alpha_{\pi}\left[\left(\kappa_{y}-\kappa_{f}\right)^{2}\right]-\rho_{\xi}\left\{\beta+\kappa_{f}\left[1-\alpha_{\pi}\left(k_{y}-k_{f}\right)\right]\right\} \quad ; \quad K\left(\rho_{\xi}\right)=\frac{\kappa_{\theta}-\alpha\left(1-\rho_{\xi}\right) \kappa_{f}}{D\left(\rho_{\xi}\right)}$

${ }^{24}$ And $\Gamma=\frac{\left(1-\alpha_{\psi}\right) \xi_{0}}{(1-\rho)} \frac{D\left(\alpha_{\theta}, 1\right)}{D(+\infty, 1)} \frac{1-\beta}{1-\rho \beta} \alpha_{\pi} \kappa_{\theta}^{2}\left(\frac{1}{D\left(\alpha_{\theta}, 1\right)}-\frac{1}{D\left(\alpha_{\theta}, \rho\right)}\right)$

${ }^{25}$ This effect is visible through the domestic consumption distortion that results from the exogenous risk premium shock $\bar{\theta}_{t}=-\frac{\zeta_{0}}{1-\rho}\left(\rho^{t}-\frac{1-\beta}{1-\rho \beta}\right)$.
} 
in increasing the interest rate and letting the currency depreciate instantly, which would lead to a positive output gap. ${ }^{26}$ These imbalances then recede as the shock vanishes: the output gap is positive, but starts decreasing; inflation is negative, but starts increasing; and the currency, which depreciated on impact, is appreciating.

Following a positive risk premium shock, FX intervention can lean against the wind: selling reserves reduces the endogenous risk premium, lowering the interest rate faced by domestic households. FX intervention limits the magnitude of the interest rate hike and exchange rate devaluation required after the shock, thus stabilizing output and inflation as well as supporting domestic consumption. However, as explained in Section III.G, FX intervention generates an external imbalance that needs to be offset in the future. As a result, optimal FX intervention has to trade off between the stabilization objective and the cost of external imbalances.

Our closed-form formula enables us to understand how optimal foreign exchange intervention is chosen along this trade-off. The optimal choice for the (endogenous) risk-premium $\psi_{t}$ is decomposed as follows:

$$
\psi_{t}=-[\underbrace{\alpha_{\psi}}_{\begin{array}{c}
\text { terms of trade } \\
\text { effect }
\end{array}}+\underbrace{\left(1-\alpha_{\psi}\right)\left(1-\frac{D(+\infty, \rho)}{D\left(\alpha_{\theta}, \rho\right)}\right)}_{\begin{array}{c}
\text { trade-off between } \\
\text { stabilizing consumption and } \\
\text { generating an external imbalance }
\end{array}}] \xi_{t}
$$

- the terms of trade effect:

As explained in Section III.F, FX interventions can stabilize the terms of trade. The first component in equation (20) represents this effect, i.e. the endogenous risk premium is chosen so as to offset the shock to the exogenous risk premium;

- the trade-off between stabilizing consumption and generating an external imbalance:

- Stabilizing consumption would call for FX intervention to completely offset the exogenous risk premium, i.e. $\psi_{t}=-\xi_{t}$. This would occur if $D\left(\alpha_{\theta}, \bullet\right)=+\infty$, i.e. if FX intervention were perfectly efficient. ${ }^{27}$

- But FX intervention also induces external imbalances that require future repayments, which is why $\psi_{t}$ cannot fully offset $\xi_{t}$.

This trade-off has to weigh the benefits of stabilizing consumption and the terms of trade vs. the cost of external imbalances. The trade-off is captured by the ratio $\frac{D(+\infty, \rho)}{D\left(\alpha_{\theta}, \rho\right)}$. This ratio,

\footnotetext{
${ }^{26}$ Adding a constraint that $\hat{\theta}_{t}=0$ to the optimization problem of the central bank would make the problem collapse to that of Gali and Monacelli (2008), with the central bank facing standard cost-push shocks.

${ }^{27}$ In the case where $D\left(\alpha_{\theta}, \bullet\right)=+\infty$, Proposition 1 shows that output and inflation are 0 .
} 
which is always smaller than 1, is a measure of the efficiency of FX intervention because it is the ratio of $1 / D\left(\alpha_{\theta}, \rho\right)$, which parametrizes the response of inflation and output to the shock, and $1 / D(+\infty, \rho)$, which would parametrize the response of inflation and output to the shock if FX intervention was impossible (e.g. if the cost of external imbalances was prohibitive).

\section{B. Simulations}

We calibrate our numerical exercise using the same parameters as those in Farhi and Werning (2014), who run a similar exercise to analyze the efficiency of capital controls and follow the calibration of Gali and Monacelli (2005). We thus set $\sigma=\gamma=\eta=1$ consistently with the Cole-Obstfeld parametrization that we used to derive our analytical results. We assume that $\phi=3$, which implies a Frisch elasticity of labor supply of $1 / 3$. We also assume that the price mark-up is equal to 1.2, which implies an elasticity of substitution between differentiated goods (from the same country) $\epsilon$ equal to 6 .

$\beta$ is set at 0.96 , corresponding to a riskless annual return of about $4 \%$ in the steady state. The parameter $\delta$ for price stickiness is taken equal to $0.75^{4}$ a value consistent with an average period of one year and a half between price adjustments. We also take an intermediate value for the degree of openness of the economy, $\alpha=0.2$, which roughly matches the ratio of imports to GDP in Brazil (around 15\%) and India (around 20\%).

More specific to our analysis, the financial accelerator parameter is set to $\mu=0.2$, following Mendoza (2010) — at each period, working capital requirements represent $20 \%$ of the value of the output produced. Finally, as in Farhi and Werning (2014), the economy is hit with a $5 \%$ risk premium shock whose half-life is 2 years.

We compare in Figure 1 the allocation in which the central bank can only use conventional monetary policy (black line) to the allocation in which the central bank can use both conventional monetary policy and FX intervention (green line). When only monetary policy is allowed, a risk premium shock provokes a large depreciation of the exchange rate and forces the central bank to increase the interest rate to compensate foreign investors (see equation (4)). This policy reaction leads to a large trade surplus (since the currency has depreciated) and a large drop in domestic consumption, with relatively small net effects on domestic output and on (PPI) inflation. We see that the variables that are not directly included in the objective function (the exchange rate, the trade balance and domestic consumption) behave as shock absorbers.

As analyzed in Section IV.A, optimal foreign exchange interventions lean against the wind by decreasing the interest rate faced by domestic households and thus supporting domestic consumption. The central bank sells foreign currency reserves, reducing the endogenous risk premium by about $1.4 \%$ initially. As a result, the fall in domestic consumption is mitigated (on impact, $3.5 \%$ vs. $4.8 \%$ when FX intervention was not allowed), the trade surplus is smaller ( $2.2 \%$ vs $3 \%$ on impact) and the depreciation of the exchange rate is also substantially smaller ( $9.2 \%$ vs. $12.7 \%$ at impact). This confirms that FX intervention proves useful as a 
stabilization tool, especially following risk-premium shocks whose impact on domestic consumption, the trade balance and the nominal exchange rate can be efficiently smoothed.

We also quantify the welfare gains allowed by FX intervention by computing the welfare loss due to the exogenous risk premium shock, and comparing this welfare loss in the case where FX intervention is used with the case where it is not allowed. The welfare losses are expressed as a compensatory, per-period, percentage decline in permanent consumption (see Figure 2). As expected, welfare losses following the exogenous risk premium shock are initially increasing with the economy's openness. Indeed, the risk premium shock is similar to a shock to domestic consumption. The more open the economy, the larger the difference between consumption and output, and thus the less efficient is monetary policy after risk premium shocks. For reasonable value of openness, the steady-state consumption gains allowed by FX intervention impact are sizable (around 0.4 percent of permanent consumption for $\alpha=0.2$; see LHS panel of Figure 3), and the relative impact is important too (40 percent of the welfare losses are canceled for $\alpha=0.2$; see RHS panel of Figure 3).

However, the relative cost of FX intervention due to external imbalances is also increasing in the economy's openness. Indeed, the benefits of stabilizing output when the economy is fully open are null, and therefore the relative cost of external imbalances is infinite (see Section

III.G). From Proposition 1, we know that FX intervention is not useful $(\hat{\theta} \rightarrow 0)$ when $\alpha \rightarrow 1$ since:

$$
\alpha_{\psi} \underset{\alpha \rightarrow 1}{\longrightarrow} 0 \quad \text { and } \quad \frac{D(+\infty, \rho)}{D\left(\alpha_{\theta}, \rho\right)} \underset{\alpha \rightarrow 1}{\longrightarrow} 1
$$

As a result, when $\alpha \rightarrow 1$, the welfare losses due to risk premium shocks are identical in the two cases.

\section{FX INTERVENTION AND SPECULATIVE ATTACKS}

We now discuss the risks of equilibrium indeterminacy in the presence of a financial friction. We only consider speculative shocks (deviations in expected values), having in mind in particular self-fulfilling currency movements, when analyzing equilibrium uniqueness. Substituting for the interest rate in the Phillips Curve using the IS curve, the central bank's problem (18) becomes:

$$
\begin{aligned}
& \min _{\pi_{H, t, y_{t}, \theta_{t}}} \alpha_{\pi} \pi_{H, t}^{2}+y_{t}^{2}+\alpha_{\theta} \hat{\theta}_{t}^{2} \quad \text { s.t. } \\
& \pi_{H, t}=\left(\beta+\kappa_{f}\right) \pi_{H, t+1}^{e}+\left(\kappa_{y}-\kappa_{f}\right) y_{t}+\kappa_{f} y_{t+1}^{e}+\left(\kappa_{\theta}-\alpha \kappa_{f}\right) \hat{\theta}_{t}+\alpha \kappa_{f} \hat{\theta}_{t+1}^{e} \\
& \sum_{t=0}^{\infty} \beta^{t} \hat{\theta}_{t}=0
\end{aligned}
$$




\section{A. Optimal policy}

The extended Phillips Curve in equation (21) shows how the financial friction affects the dynamics of inflation (and thus of the exchange rate). Compared to the standard New Keynesian Phillips Curve, future inflation has a bigger weight as a determinant of current inflation (since $\kappa_{f}>0$ ), whereas the coefficient on current output is smaller (also by $\kappa_{f}$ ). The first-order conditions on $y_{t}$ and $\theta_{t}$ are: ${ }^{28}$

$$
\begin{aligned}
& \alpha_{\pi}\left(\kappa_{y}-\kappa_{f}\right) \pi_{H, t}+y_{t}=0 \\
& {\left[\kappa_{\theta}-\alpha \kappa_{f}\right] \pi_{H, t}+\alpha_{\theta} \theta_{t}+\Gamma=0}
\end{aligned}
$$

where, $\Gamma$ is, as before, the Lagrange multiplier for the intertemporal budget constraint. Domestic inflation thus obeys the following law of motion:

$$
\pi_{H, t}=\frac{\beta+\kappa_{f}-\alpha_{\pi} \kappa_{f}\left(\kappa_{y}-\kappa_{f}+\frac{\alpha\left(\kappa_{\theta}-\alpha \kappa_{f}\right)}{\alpha_{\theta}}\right)}{1+\alpha_{\pi}\left(\kappa_{y}-\kappa_{f}\right)^{2}+\frac{\alpha_{\pi}\left(\kappa_{\theta}-\alpha \kappa_{f}\right)^{2}}{\alpha_{\theta}}} \pi_{H, t+1}^{e}-\frac{\frac{\kappa_{\theta}}{\alpha_{\theta}}}{1+\alpha_{\pi}\left(\kappa_{y}-\kappa_{f}\right)^{2}+\frac{\alpha_{\pi}\left(\kappa_{\theta}-\alpha \kappa_{f}\right)^{2}}{\alpha_{\theta}}} \Gamma
$$

Equation (22) shows that optimal policy is to 'choose' a negative output gap when inflation is positive (or a positive output gap when inflation is negative) - otherwise, if the output gap and inflation were both positive, the central bank could reduce both variables by increasing the interest rate. In other words, the central bank "leans against the wind", engineering a contraction if inflation is excessive.

Similarly, for a given Lagrange multiplier, equation (23) shows that optimal policy is to choose a negative consumption gap when inflation is positive - otherwise, if the consumption gap and inflation were both positive, the central bank could reduce both variables by increasing the level of reserves and the risk premium (an increase in the risk premium decreases current consumption, and thus aggregate demand, for a given level of future consumption; see equations (6) and (7)). The central bank again "leans against the wind", increasing the level of reserves and the risk premium when inflation is positive. Conventional and unconventional policies steer inflation and output in the same direction. However, looking now at the exchange rate, the impact of an increase in the interest rate is partially offset by an increase in the endogenous risk $\left(e_{t+1}^{e}-e_{t}=i_{t}-i_{t}^{*}-\psi_{t}\right)$. Sterilized intervention thus allows the central bank to limit the effect of its conventional monetary policy on the exchange rate.

\section{B. Equilibrium Determinacy}

In the standard New Keynesian Model, optimal policy ensures equilibrium uniqueness. We show here that this result does not hold in the presence of the financial accelerator and

\footnotetext{
${ }^{28}$ Since there are no exogenous risk premium shock in this section, the total consumption distortion $\theta_{t}$ coincides with the consumption distortion resulting from foreign exchange interventions $\hat{\theta}_{t}$. We then simply refer to the total consumption distortion $\theta_{t}$ as the policy tool in this section.
} 
discuss how FX intervention can help.

\section{Proposition 2. Equilibrium Determinacy under Discretionary Policy}

Equilibrium determinacy is ensured when the Blanchard-Kahn condition is satisfied, i.e. when: 29

$$
\alpha_{\pi}>\frac{\beta+\kappa_{f}-1}{\kappa_{y}\left(\kappa_{y}-\kappa_{f}\right)+\frac{\kappa_{\theta}\left(\kappa_{\theta}-\alpha \kappa_{f}\right)}{\alpha_{\theta}}}
$$

Proof: The proof consists in applying the Blanchard-Kahn condition to equation (24).

Q.E.D.

If the coefficient of the financial accelerator is larger than $1-\beta$, equilibrium under discretionary policy can be indeterminate, a possibility absent in the standard open economy New Keynesian Model (see Gali (2008)). It is instructive to analyze the role of foreign exchange intervention in ensuring determinacy. To this aim, we first consider the case in which FX intervention is not possible.

\section{Equilibrium determinacy without FX intervention}

If FX intervention is not available, the condition for determinacy is:

$$
\alpha_{\pi}>\frac{\beta+\kappa_{f}-1}{\kappa_{y}\left(\kappa_{y}-\kappa_{f}\right)}
$$

Denoting by $X_{y}$ the size of the output loss engineered by the central bank when inflation is 1 percent (i.e. $X_{y}=\alpha_{\pi}\left(\kappa_{y}-\kappa_{f}\right)$, obtained from equation (22)), the condition for equilibrium determinacy is rewritten as:

$$
1+(\underbrace{\kappa_{y}-\kappa_{f}}_{\begin{array}{c}
\text { impact of current output } \\
\text { on current inflation }
\end{array}}+\underbrace{\kappa_{f}}_{\begin{array}{c}
\text { impact of expected output } \\
\text { on current inflation }
\end{array}}) X_{y}>\beta+\kappa_{f}
$$

or equivalenly:

$$
\kappa_{y} X_{y}>\beta+\kappa_{f}-1
$$

Intuitively, determinacy requires that, when inflation is positive, the central bank decides to engineer an economic slowdown such that the total impact on today's inflation is stronger than the impact of expected inflation on today's inflation $\beta+\kappa_{f}$ in the Phillips curve (see problem (21)). This ensures that current inflation is lower than expected inflation, ruling out equilibrium indeterminacy.

${ }^{29}$ If $\left(\kappa_{y}-\kappa_{f}\right)\left(2 \kappa_{f}-\kappa_{y}\right)+\frac{\left(\kappa_{\theta}-\alpha \kappa_{f}\right)\left(2 \alpha \kappa_{f}-\kappa_{\theta}\right)}{\alpha_{\theta}}>0$, which implies $\mu>\frac{1}{2}$, the condition has an upper bound: $\frac{\beta+\kappa_{f}-1}{\kappa_{y}\left(\kappa_{y}-\kappa_{f}\right)+\frac{\kappa_{\theta}\left(\kappa_{\theta}-\alpha \kappa_{f}\right)}{\alpha_{\theta}}}<\alpha_{\pi}<\frac{\beta+\kappa_{f}+1}{\left(\kappa_{y}-\kappa_{f}\right)\left(2 \kappa_{f}-\kappa_{y}\right)+\frac{\left(\kappa_{\theta}-\alpha \kappa_{f}\right)\left(2 \alpha \kappa_{f}-\kappa_{\theta}\right)}{\alpha_{\theta}}}$ 
In absence of the financial accelerator (i.e. $\kappa_{f}=0$ ), the equilibrium is always unique, because $\beta-1<0$. The central bank's optimal policy would be to hike interest rates and engineer a recession if confronted with speculative increases in inflation. The negative output gap would lower inflation below what is expected by firms, thus ruling out self-fulfilling inflation and currency movements. ${ }^{30}$

However, with a financial friction, the decision to increase the interest rate would also increase firms' marginal costs. The recession must thus be deeper, or the sensitivity of inflation to the output gap higher, to ensure marginal costs are sufficiently reduced. If the weight of inflation in the loss function is too low, the slowdown engineered by the central bank may be insufficient to offset the impact of the financial friction on inflation. Current inflation ends up being too high, thus justifying a continuum of self-fulling equilibria.

\section{Equilibrium determinacy with FX intervention}

We now reintroduce FX intervention, and using equation (23), we define $X_{\theta}=\frac{\alpha_{\pi}}{\alpha_{\theta}}\left(\kappa_{\theta}-\alpha \kappa_{f}\right)>0$ as the marginal increase in the consumption wedge for a decrease in the rate of inflation. Reacting to an expected appreciation of the currency, the central bank can accumulate reserves to increase the risk premium. For a given increase in the interest rate, an increase in the risk premium would depreciate the currency. The Blanchard-Kahn condition becomes:

$$
\kappa_{y} X_{y}+\kappa_{\theta} X_{\theta}>\beta+\kappa_{f}-1
$$

The rationale is as before. The optimal use of reserves (and its use in period $t+1$ ) can mitigate current inflation, the more so if the effect of the instrument on current and future inflation is high (i.e., $\kappa_{\theta}$ is high) and if the central bank uses this instrument aggressively (if $X_{\theta}$ is high).

Figure 4 shows the zone of indeterminacy provided by conditions (25) and (27). When using reserves comes at no cost ( $\alpha_{\theta}=0$, see left-hand chart), or when reserves have a strong effect on inflation ( $X_{\theta}$ is high, see right-hand chart), the risk of indeterminacy is eliminated, even if the central bank is not willing to hike interest rates and engineer recessions. The downward sloping frontier in the right-hand chart depicts the trade-off: for a given impact of the interest rate, the central bank must either be willing to engineer large recessions ( $X_{y}$ is large) or to be activist with its FX reserves ( $X_{\theta}$ large).

\footnotetext{
${ }^{30}$ More precisely, inflation is always lower than future inflation in the absence of a financial accelerator; thus, the only non-explosive path for inflation (and the exchange rate) is the one with zero inflation. This is why when the Blanchard-Khan condition is always satisfied in this case.
} 


\section{Conclusion}

Although empirical research has sometimes had difficulties in establishing the effectiveness of sterilized intervention, many central banks, especially but not exclusively in emerging market economies, intervene in the FX markets. An obvious question, therefore, is how FX intervention should interact with interest rate policy, and in particular whether FX intervention helps stabilize the economy following exogenous shocks to international capital flows, and whether FX intervention improves the credibility of inflation targeting. This paper provides answers to these questions in the context of an open economy New Keynesian Model.

To justify the use of FX intervention, we extend the open economy New Keynesian Model with a friction in international capital markets. Foreign investors's preferences for domestic bonds is a function of "VIX" risk premium shocks, which increase the cost of borrowing for domestic households and affect domestic consumption and thus break the divine coincidence. We show that FX intervention helps stabilize domestic allocation following this type of shock. FX intervention is particularly efficient in stabilizing domestic consumption, the exchange rate, and the trade balance. We also show that FX intervention is efficient from a welfare point of view, and can mitigate the welfare losses due to these risk premium shocks.

We finally note that self-fulfilling currency movements are possible in the New Keynesian model with a working capital requirement, along the lines of speculative attack models à la Aghion et al. (2000). We show that in that model, the central bank's ability to use FX intervention reduces the range of parameters for which equilibrium indeterminacy occurs. If FX intervention is very effective, or if the central bank has a strong preference for intervening on the FX market, the central bank can rule out indeterminacy even if it is not perceived to be sufficiently active with conventional monetary policy. 


\section{REFERENCES}

Aghion, Philippe, Philippe Bacchetta, and Abhijit Banerjee, 2000, "A simple model of monetary policy and currency crises," European Economic Review, Vol. 44. and , 2004, "A corporate balance-sheet approach to currency crises," Journal of Economic Theory, Vol. 119.

Alichi, Ali, Jaromir Benes, Joshua Felman, Irene Feng, Charles Freedman, Douglas Laxton, Evan Tanner, David Vavra, and Hou Wang, 2015, Frontiers of Monetary Policymaking: Adding the Exchange Rate as a Tool to Combat Deflationary Risks in the Czech Republic, IMF Working Paper 15/74. Washington DC: IMF

Alla, Zineddine, Raphael Espinoza, and Atish Rex Ghosh, 2016, "Unconventional Monetary Policy in the New Keynesian Model," IMF Working Paper 16/58. Washington DC: IMF

Backus, David, and Patrick Kehoe, 1989, "On the Denomination of Government Debt," Journal of Monetary Economics, pp. 35-376.

Basu, Suman, Atish Rex Ghosh, Jonathan Ostry, and Pablo Winant, 2017, "Managing Capital Outflows: The Role of Foreign Exchange Intervention," forthcoming, IMF Economic Review.

Benes, Jaromir, Andrew Berg, Rafael A Portillo, and David Vavra, 2015, "Modeling sterilized interventions and balance sheet effects of monetary policy in a New-Keynesian framework," Open Economies Review, Vol. 26, No. 1, pp. 81-108.

Blanchard, Olivier, Francesco Giavazzi, and Filipa Sa, 2005, "International Investors, the U.S. Current Account, and the Dollar," Brookings Papers of Economic Activity, Vol. 1, pp. 1-66.

Branson, W.H., and D. Henderson, 1985, Handbook of International Economics (R. Jones and P. Kenen (eds), North-Holland Publishing).

Calvo, Guillermo, and Carmen Reinhart, 2002, "Fear of floating," Quarterly Journal of Economics, Vol. 117, No. 2, pp. 379-408.

Cavallino, Paolo, 2016, "Capital Flows and Foreign Exchange Intervention," Available at SSRN 2529497.

Clarida, Richard, Jordi Gali, and Mark Gertler, 1999, "The Science of Monetary Policy: A New Keynesian Perspective," Journal of Economic Literature, Vol. XXXVII, pp. 3-24.

Cole, Harold L., and Maurice Obstfeld, 1991, "Commodity Trade and International Risk Sharing: How Much Do Financials Markets Matter," Journal of Monetary Economics, Vol. 28, No. 1, pp. 3-24.

Curdia, V, and Michael Woodford, 2011, "The central-bank balance sheet as an instrument of monetary policy," Journal of Monetary Economics, Vol. 28, No. 1, pp. 54-79. 
Disyatat, Piti, and Gabriele Galati, 2007, "The effectiveness of foreign exchange intervention in emerging market countries: Evidence from the Czech koruna," Journal of International Money and Finance, Vol. 26, pp. 383-402.

Dominguez et al., 2013, "Do Sales of Foreign Exchange Reserves Lead to Currency Appreciation?," Journal of Money, Credit and Banking, Vol. 45, No. 5, pp. 867-90.

Dominguez, Kathryn, 2006, "When Do Central Bank Interventions Influence Intra-daily and Longer-term Exchange Rate Movements?," Journal of International Money and Finance, Vol. 25, pp. 1051-71.

and Jeffrey Frankel, 2005, "Does Foreign Exchange Intervention Matter? The Portfolio Effect," American Economic Review, Vol. 83, pp. 1356-69.

Farhi, Emmanuel, and Ivan Werning, 2012, "Dealing with the Trilemma: Optimal Capital Controls with Fixed Exchange Rates." , and ,2014, "Dilemma Not Trilemma: Capital Controls and Exchange Rates with Volatile Capital Flows," IMF Economic Review, Vol. 62, No. 4, pp. 569-605.

Gabaix, Xavier, and Matteo Maggiori, 2015, "International liquidity and exchange rate dynamics," Quarterly Journal of Economics, Vol. 130, No. 3.

Gali, Jordi, 2008, Monetary Policy, Inflation, and the Business Cycle (Princeton University Press).

and Tommaso Monacelli, 2005, "Monetary Policy and Exchange Rate Volatility in a Small Open Economy," Review of Economic Studies, Vol. 72, No. 3, pp. 707-734. and __, 2008, "Optimal monetary and fiscal policy in a currency union," Journal of International Economics, Vol. 76, No. 1, pp. 116-132.

Ghosh, A. R., 1992, "Is It Signaling? Exchange Intervention and the Dollar-Deutschemark Rate," Journal of International Economics, Vol. 32, pp. 170-80.

Ghosh, A. R, J.D. Ostry, and M.S. Qureshi, 2017, "Managing the Tide: How Do Emerging Markets Respond to Capital Flows?," IMF Working Paper 17/69. Washingon DC: IMF

IMF, 2013, Czech Republic 2013 Article IV Consultation (International Monetary Fund). 2014, Switzerland 2014 Article IV Consultation (International Monetary Fund).

Itskhoki, Oleg, and Dmitry Mukhin, 2017, "Exchange rate disconnect in general equilibrium,” NBER Working Paper 23401, Cambridge MA: NBER.

Jeanne, Olivier, and Romain Ranciere, 2011, “The Optimal Level of International Reserves for Emerging Market Countries: A New Formula and Some Applications," Economic Journal, Vol. 121, No. 1, pp. 905-930.

Kouri, Pentti JK, 1976, "The exchange rate and the balance of payments in the short run and in the long run: A monetary approach," The Scandinavian Journal of Economics, pp. 280-304. 
Krugman, Paul, 1999, "Balance Sheets, the Transfer Problem, and Financial Crises," International Tax and Public Finance, Vol. 6, pp. 459-472.

Kumhof, Michael, 2010, "On the theory of sterilized foreign exchange intervention," Journal of Economic Dynamics and Control, Vol. 34, No. 8, pp. 1403-1420.

Melvin et al, 2009, "Exchange rate management in emerging markets: Intervention via an electronic limit order book," Journal of International Economics, Vol. 79, pp. 54-63.

Mendoza, Enrique G, 2010, "Sudden stops, financial crises, and leverage," The American Economic Review, Vol. 100, No. 5, pp. 1941-1966.

Menkhoff, Lukas, 2013, "Foreign Exchange Intervention in Emerging Markets: A Survey of Empirical Studies," World Economy, Vol. 36, No. 9, pp. 1187-1208.

Neely, C., 2005, “An Analysis of Recent Studies of the Effect of Foreign Exchange Intervention,” Federal Reserve Bank of St. Louis Review, Vol. 87, No. 6, pp. 685-717.

Obstfeld, Maurice, 1986, "Exchange Rate Dynamics Redux," American Economic Review, Vol. 76, pp. 72-81.

Sarno, Lucio, and Mark Taylor, 2001, "Official Intervention in the Foreign Exchange Markets: Is It Effective and, If So, How Does It Work?," Journal of Economic Literature, Vol. 34, No. 3, pp. 839-68.

Schmitt-Grohe, Stephanie, and Martin Uribe, 2003, "Closing small open economy models," Journal of International Economics, Vol. 61, No. 1, pp. 163-185.

Surico, P., 2008, "The Cost Channel of Monetary Policy and Indeterminacy," Macroeconomic Dynamics, Vol. 12, No. 5, pp. 724-735.

Woodford, Michael, 2003, Interest and Prices: Foundations of a Theory of Monetary Policy (Princeton University Press). 2012, "Inflation Targeting and Financial Stability," NBER Working Paper, No. 17967. Cambridge MA: NBER 


\section{APPENDIX I. FIRST-ORDER CONDITIONS FOR CALVO PRICE SETTING}

In the non-linearized model, the Calvo Price setting first-order conditions can be expressed as follow:

$$
\frac{1-\delta\left(\Pi_{H, t}\right)^{\varepsilon-1}}{1-\delta}=\left(\frac{F_{t}}{K_{t}}\right)^{\varepsilon-1}
$$

where

$$
K_{t}=\frac{\varepsilon}{\varepsilon-1} \frac{1+\tau}{A_{H}} Y_{t} N_{t}^{\phi}+\delta \beta \Pi_{H, t+1}^{\varepsilon} K_{t+1}, \quad F_{t}=Y_{t} C_{t}^{-\sigma} S_{t}^{-1} Q_{t}+\delta \beta \Pi_{H, t+1}^{\varepsilon-1} F_{t+1},
$$

with PPI inflation denoted $\Pi_{H, t+1}=\frac{P_{H, t+1}}{P_{H, t}}$, and price dispersion $\Delta_{t}$ following the law of motion:

$$
\Delta_{t}=h\left(\Delta_{t-1}, \Pi_{H, t}\right), \quad h(\Delta, \Pi)=\delta \Delta \Pi^{\varepsilon}+(1-\delta)\left(\frac{1-\delta \Pi^{\varepsilon-1}}{1-\delta}\right)^{\varepsilon /(\varepsilon-1)}
$$

\section{APPENDIX II. DERIVATION OF THE INTERTEMPORAL BUDGET CONSTRAINT}

Assuming that foreign countries are symmetric, Home's budget constraint at date $t$, which is derived by adding the budget constraints of:

- the households:

$$
P_{t} C_{t}+D_{t+1}^{h}+S_{t+1}^{b}+T_{t}^{f i n} \leq\left(1+i_{t-1}\right)\left(D_{t}^{h}+S_{t}^{b}\right)+W_{t} N_{t}+\Pi_{t}+T_{t}^{f i r m}+T_{t}^{g o v}
$$

- the central bank:

$$
E_{t} R_{t+1}^{*}-E_{t}\left(1+i_{t-1}^{*}\right) \Xi_{t-1} R_{t}^{*}=S_{t+1}^{b}-\left(1+i_{t-1}\right) S_{t}^{b}
$$

- the government:

$$
\frac{1+i_{t-1}}{\Psi_{t-1}} D_{t}^{f}+\left(1+i_{t-1}\right)\left(D_{t}^{h}+S_{t}^{b}\right)+T_{t}^{g o v} \leq D_{t+1}^{f}+D_{t+1}^{h}+\tau W_{t} N_{t}+T_{t}^{f i n}
$$

The consolidated budget contraint is then:

$$
E_{t} R_{t+1}^{*}-E_{t}\left(1+i_{t-1}^{*}\right) \Xi_{t-1} R_{t}^{*}+\frac{1+i_{t-1}}{\Psi_{t-1}} D_{t}^{f} \leq D_{t+1}^{f}+P_{H, T} Y_{t}-P_{t} C_{t}
$$


We define the country net foreign asset $\operatorname{position}^{31}$ and the trade balance as follows:

$$
N F A_{t}=\frac{\left(1+i_{t-1}^{*}\right) \Xi_{t-1} E_{t}}{P_{F, t} C_{t}^{* \sigma}}\left[R_{t}^{*}-\frac{D_{t}^{f}}{E_{t-1}}\right], \quad N X_{t}=P_{H, t} Y_{t}-P_{t} C_{t}
$$

Introducing the net foreign asset position and the trade balance in the consolidated budget constraint, we have:

$$
\frac{P_{F, t+1} C_{t+1}^{*}{ }^{\sigma}}{\left(1+i_{t}^{*}\right) \Xi_{t}} N F A_{t+1}-P_{F, t} C_{t}^{* \sigma} N F A_{t}=N X_{t}
$$

The Euler equation for foreign households is:

$$
1+i_{t}^{*}=\beta^{-1}\left(\frac{C_{t+1}^{*}}{C_{t}^{*}}\right)^{\sigma} \frac{P_{F, t+1}}{P_{F, t}}
$$

Using the two above equations, we then have:

$$
N F A_{t}=-\frac{1}{P_{F, t} C_{t}^{*}} N X_{t}+\frac{\beta}{\Xi_{t}} N F A_{t+1}
$$

\section{APPENDIX III. DERIVATION OF THE LOSS FUNCTION}

We first have the exact relationship:

$$
c_{t}=(1-\alpha) s_{t}+\theta_{t}
$$

And the following second-order approximation of the goods market clearing condition $Y_{t}=S_{t} C^{*}\left[(1-\alpha) \Theta_{t}+\alpha\right]$ :

$$
y_{t}=s_{t}+(1-\alpha) \theta_{t}+\frac{1}{2} \alpha(1-\alpha) \theta_{t}^{2}
$$

We use this result to derive:

$$
c_{t}=(1-\alpha) y_{t}+\alpha(2-\alpha) \theta_{t}-\frac{1}{2} \alpha(1-\alpha)^{2} \theta_{t}^{2}
$$

\footnotetext{
${ }^{31}$ Normalizing by foreign consumption and taking the foreign price at home $P_{F, t}$ as the numeraire.
} 
By the labor market clearing condition, we have up to second-order approximation:

$$
n_{t}=y_{t}+\log \Delta_{t}^{P}+\frac{1}{2} y_{t}^{2}
$$

By Woodford (2003), we have:

$$
\sum_{t=0}^{\infty} \beta^{t} \log \Delta_{t}^{P}=\frac{\varepsilon_{P}}{2 \lambda_{P}} \int_{0}^{\infty} e^{-\rho t} \pi_{H, t}^{2}
$$

Finally, using $\bar{N}^{1+\phi}=(1-\alpha)$ and integrating over time, we have the following expression for the objective function:

$$
\begin{aligned}
& \sum_{t=0}^{\infty} \beta^{t}\left(\frac{U_{t}-\bar{U}}{C U_{c}}\right)= \\
& -\frac{(1-\alpha)(1+\phi)}{2} \int_{0}^{\infty} e^{-\rho t}\left\{\alpha_{\pi} \pi_{H, t}^{2}+y_{t}^{2}-\frac{2 \alpha(2-\alpha)}{(1-\alpha)(1+\phi)} \theta_{t}+\alpha \frac{1-\alpha}{1+\phi} \theta_{t}^{2}\right\}
\end{aligned}
$$

We now use a second order approximation of the budget constraint to replace the linear term $\theta_{t}$ in the expression above. We find:

$$
-\sum_{t=0}^{\infty} \beta^{t} \theta_{t}=\sum_{t=0}^{\infty} \beta^{t}\left[\frac{1}{2} \theta_{t}^{2}+\left(\bar{\theta}_{0}-\bar{\theta}_{t}\right) \theta_{t}\right]+\text { t.i.p. }
$$

The sum $\sum_{t=0}^{\infty} \beta^{t} \theta_{t}$ only has second order terms in $\theta_{t}$, so we can get rid of $\bar{\theta}_{0} \sum_{t=0}^{\infty} \beta^{t} \theta_{t}$ when developing up to the second order the welfare loss.

We then get the following loss function (up to additive terms independent of policy and multiplicative constants):

$$
\frac{1}{2} \sum_{t=0}^{\infty} \beta^{t}\left[\alpha_{\pi} \pi_{H, t}^{2}+y_{t}^{2}+\alpha_{\theta}\left[\hat{\theta}_{t}+\alpha_{\psi} \bar{\theta}_{t}\right]^{2}\right]
$$

where

$$
\alpha_{\pi}=\frac{\varepsilon_{P}}{\lambda_{P}(1+\phi)}, \quad \alpha_{\theta}=\frac{\alpha}{1+\phi}\left(\frac{2-\alpha}{1-\alpha}+1-\alpha\right), \quad \alpha_{\psi}=\frac{1-\alpha}{\frac{2-\alpha}{1-\alpha}+1-\alpha}
$$




\section{Appendix IV. Proof of Proposition 1}

For analytical convenience, we express the consumption distortion $\theta_{t}$ in deviation from the steady state. The problem boils down to:

$$
\begin{gathered}
\min _{\pi_{H, t}, y_{t}, i_{t}, \psi_{t}, \theta_{t}, e_{t}} \alpha_{\pi} \pi_{H, t}^{2}+y_{t}^{2}+\alpha_{\theta}\left[\theta_{t}-\left(1-\alpha_{\psi}\right) \bar{\theta}_{t}\right]^{2} \text { s.t. } \\
\pi_{H, t}=\beta \pi_{H, t+1}^{e}+\kappa_{y} y_{t}+\kappa_{\theta} \theta_{t} \\
\sum_{t=0}^{\infty} \beta^{t} \theta_{t}=0
\end{gathered}
$$

Proof. The first-order conditions on the two instruments are:

$$
\alpha_{\pi} \kappa_{y} \pi_{H, t}+y_{t}=0 \quad \alpha_{\pi} \kappa_{\theta} \pi_{H, t}+\alpha_{\theta}\left[\theta_{t}-\left(1-\alpha_{\psi}\right) \bar{\theta}_{t}\right]-\Gamma=0
$$

Since $\bar{\theta}_{t}=\frac{\xi_{0}}{1-\rho}\left(\frac{1-\beta}{1-\rho \beta}-\rho^{t}\right)$ for exponentially decreasing risk premium shocks: $\xi_{t}=\xi_{0} \rho^{t}$, substituting the first-order conditions in the Phillips Curve and iterating, we get:

$$
\begin{gathered}
\pi_{H, t}=\frac{\kappa_{\theta}\left(1-\alpha_{\psi}\right) \xi_{0}}{1-\rho}\left(\frac{1-\beta}{1-\rho \beta} \frac{1}{D(1)}-\frac{1}{D(\rho)} \rho^{t}\right)+\frac{\kappa_{\theta}}{\alpha_{\theta} D(1)} \Gamma \\
\text { with } \Gamma=\frac{\left(1-\alpha_{\psi}\right) \xi_{0}}{(1-\rho)} \frac{D(1)}{D^{y}(1)} \frac{1-\beta}{1-\rho \beta} \alpha_{\pi} \kappa_{\theta}^{2}\left(\frac{1}{D(1)}-\frac{1}{D(\rho)}\right) \\
y_{t}=-\alpha_{\pi} \kappa_{y} \pi_{H, t} \quad \text { and } \quad \theta_{t}=\frac{\left(1-\alpha_{\psi}\right) \xi_{0}}{1-\rho} \frac{D^{y}(\rho)}{D(\rho)}\left(\frac{1-\beta}{1-\rho \beta}-\rho^{t}\right)
\end{gathered}
$$

Since $\bar{\theta}_{t}=\frac{\xi_{0}}{1-\rho}\left(\frac{1-\beta}{1-\rho \beta}-\rho^{t}\right)$, we find that the foreign exchange intervention impact on consumption can be described as follows:

$$
\hat{\theta}_{t}=\frac{\xi_{0}}{1-\rho}\left[\left(1-\alpha_{\psi}\right) \frac{D^{y}(\rho)}{D(\rho)}-1\right]\left(\frac{1-\beta}{1-\rho \beta}-\rho^{t}\right)
$$

Q.E.D. 
Figure 1. The Effects of a Risk-Premium Shock under Optimal Discretionary Policy
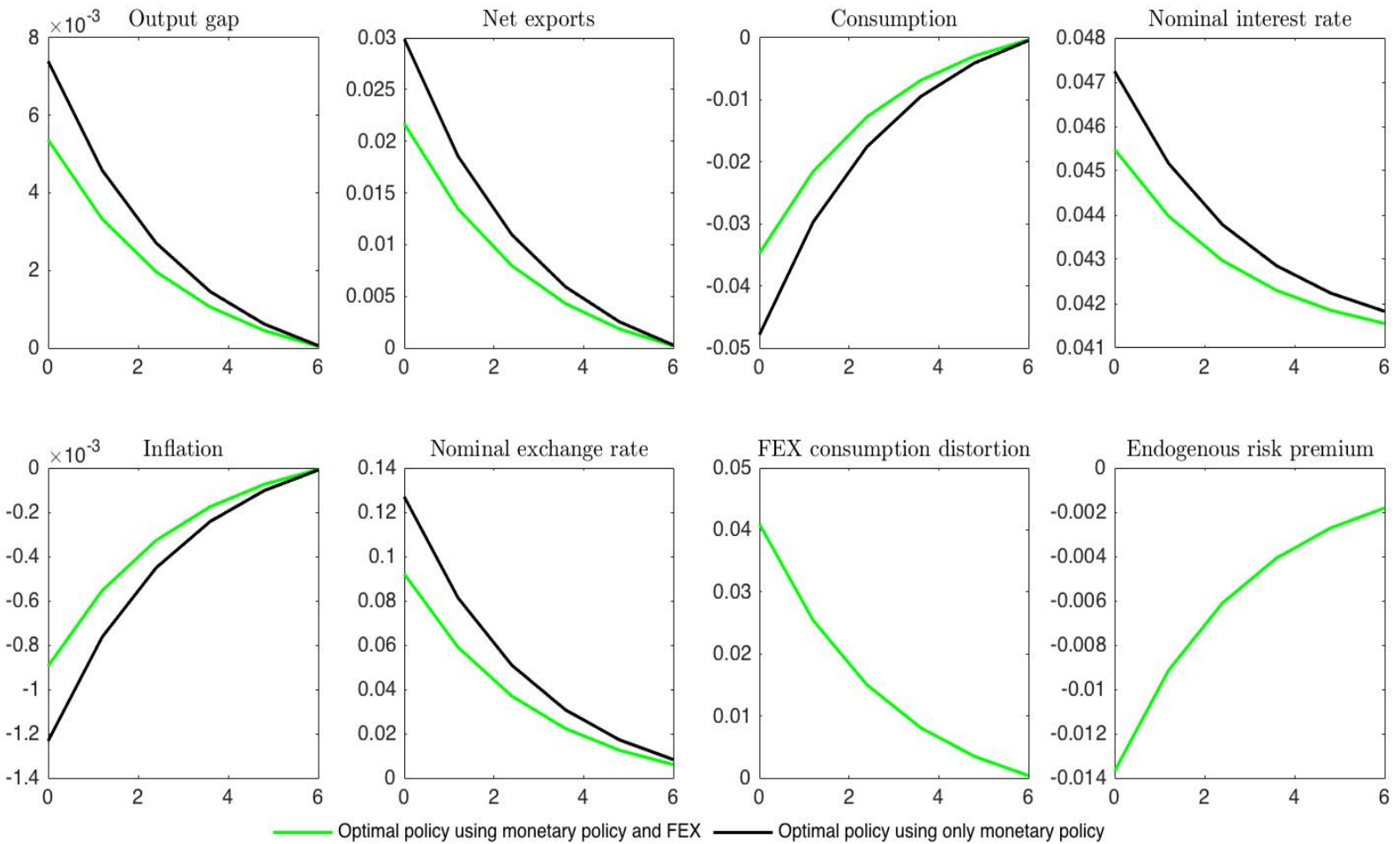

Figure 2. Welfare Losses following an Exogenous Risk Premium Shock (5 percent shock, two years' half-life)

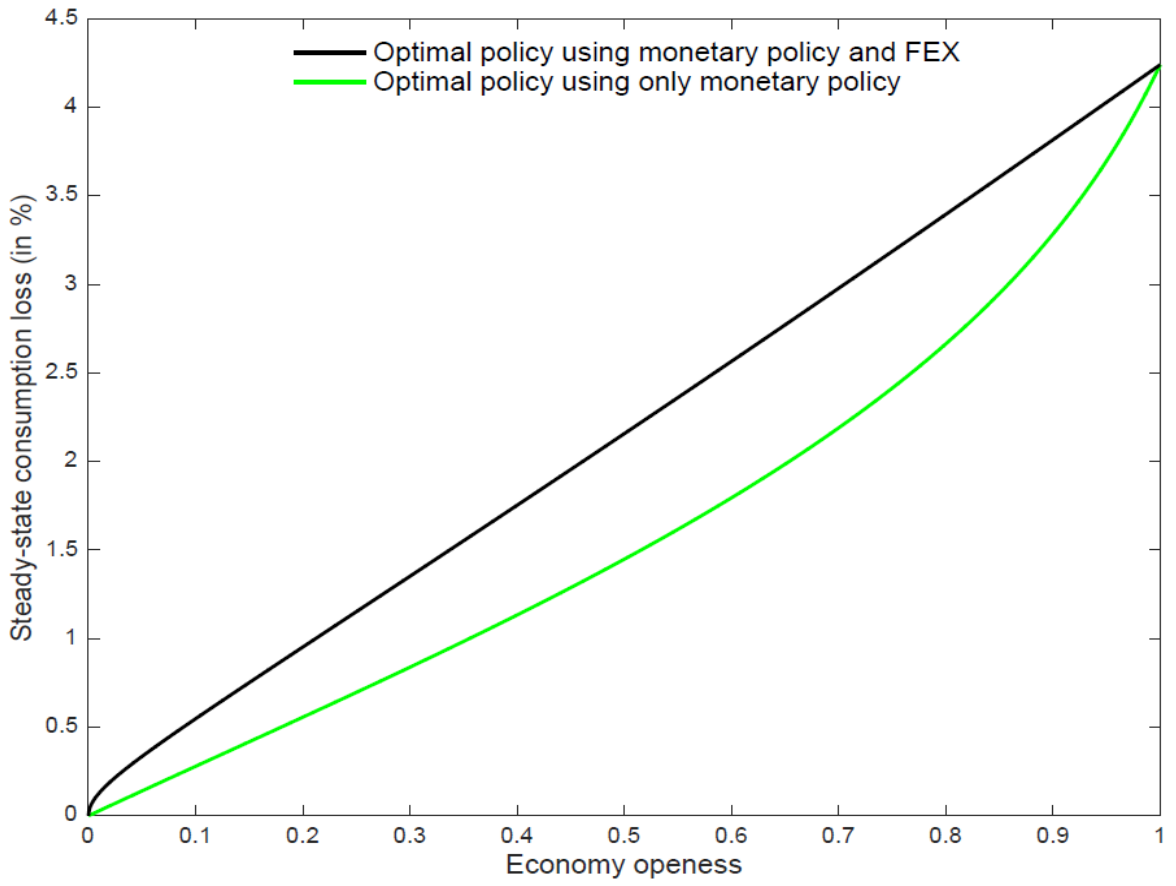


Figure 3. Welfare Gains from using FX Intervention following an Exogenous Risk Premium Shock
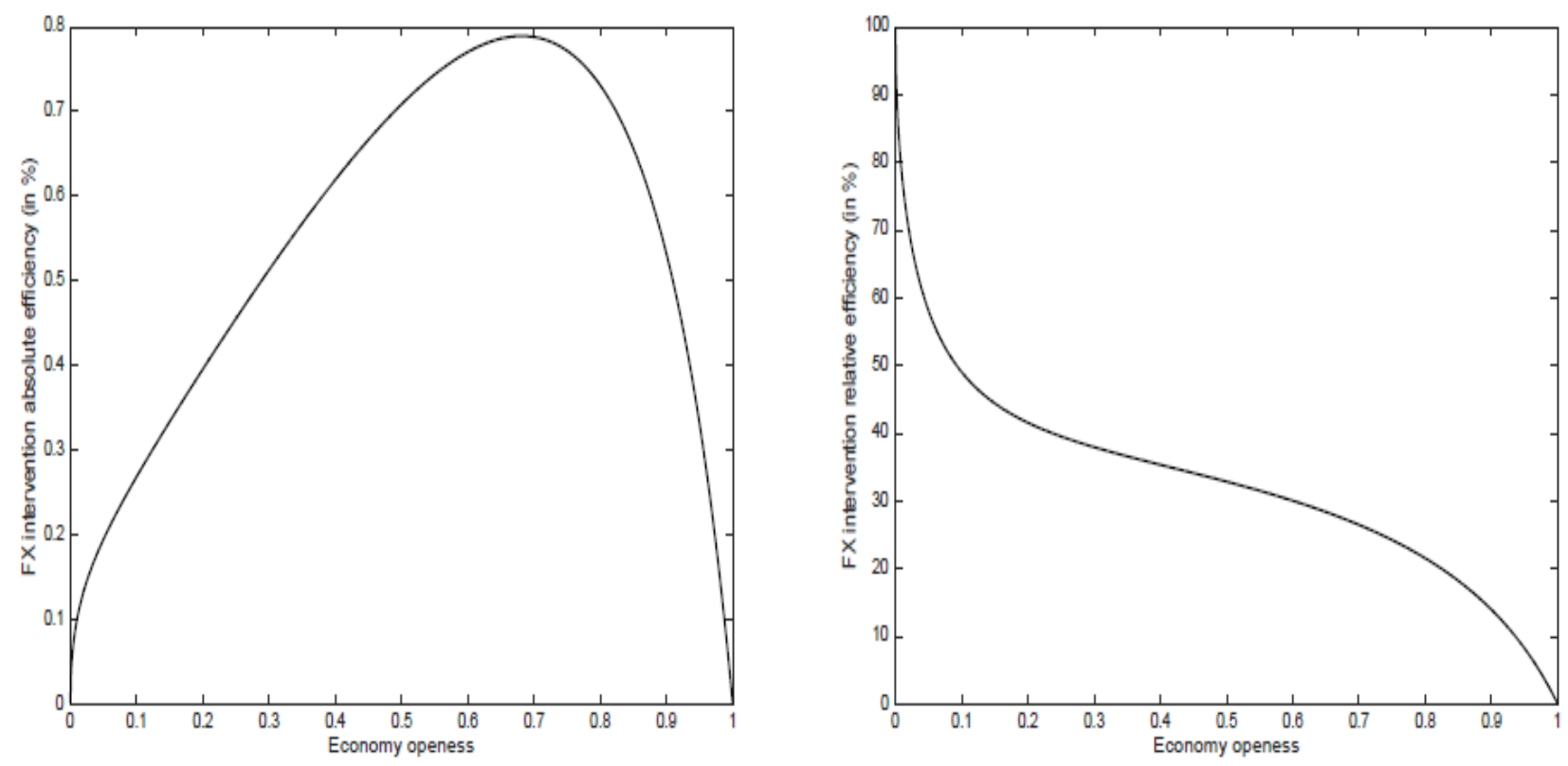

Figure 4. Optimal Policy Determinacy Condition
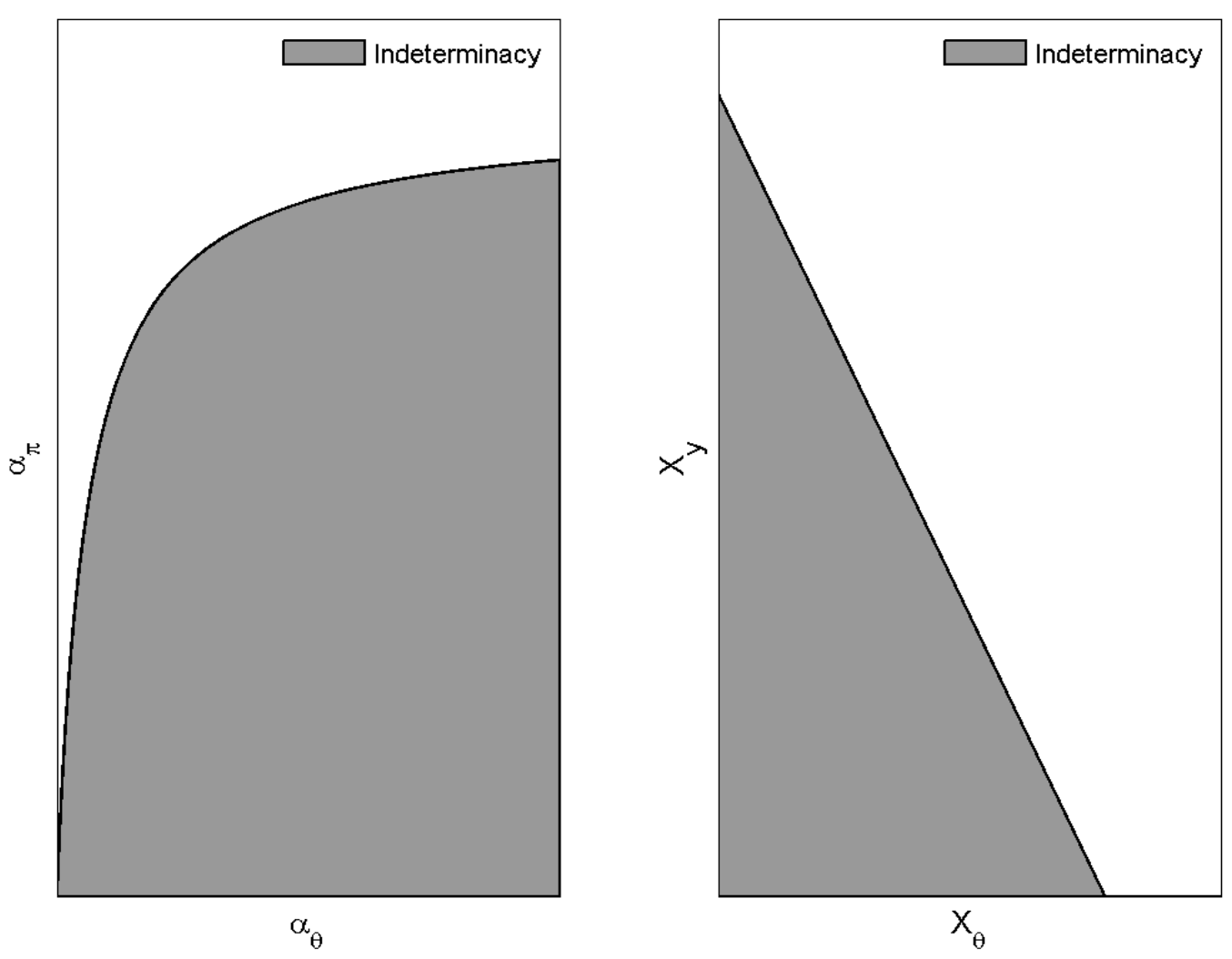

CInternational Monetary Fund. Not for Redistribution 